\title{
Evaluation of the synergistic erosion- corrosion behaviour of HVOF thermal spray coatings
}

\author{
Tom Peat ${ }^{a}$, Alexander Galloway ${ }^{a}$, Athanasios Toumpis ${ }^{a}$, David Harvey ${ }^{b}$ \\ ${ }^{\mathrm{a}}$ Department of Mechanical \& Aerospace Engineering, University of Strathclyde, James Weir \\ Building, 75 Montrose Street, Glasgow G1 1XJ, United Kingdom \\ ${ }^{\mathrm{b}}$ TWI, Granta Park, Cambridge, CB21 6AL, United Kingdom
}

\section{Abstract}

The present study examines three High Velocity Oxy Fuel deposited coatings, Tungsten Carbide, Chromium Carbide and Aluminium Oxide, under slurry erosion-corrosion conditions. Coatings produced in this manner typically exhibit superior density and hardness over alternative thermal spray technologies, therefore are suitable for use in corrosive and highly erosive environments. The scope of the study concentrates on isolation of the contributing factors of erosion, corrosion and synergy through applied electrochemistry, as well as metallographic analysis to evaluate the mechanisms causing coating degradation. The aim of which is to provide comprehensive data on the performance of the mentioned coatings under erosion-corrosion in conditions representing a flowing environment. Results demonstrate the breakdown of Chromium Carbide and Aluminium Oxide coatings result in enhanced mass loss over the uncoated S355 steel. Despite this, results have shown Tungsten Carbide with a Cobalt binder to be an effective protective coating, resulting in a significant reduction in total material loss over uncoated S355 steel. 
Keywords

Thermal spray coatings; Corrosion; Slurry erosion; Synergy; Wear; Electrochemistry 


\section{Introduction}

Erosion-corrosion is a major cause of material degradation within pump and pipeline components transporting erosive slurry at high velocities [1-3]. In order to combat this degradation, applied hard surface coatings provide protection against erosive particulates within the slurry; one such technology is High Velocity Oxy Fuel (HVOF). A derivative of flame spraying, HVOF is used to deposit wear resistant coatings onto a variety of substrate materials [4]. The deposition process involves spraying molten or semi-molten powder particles at high velocities onto the substrate surface [5]. The high kinetic energies generated by the spraying process result in a very dense coating that is well bonded to the substrate and resistant to mechanical wear and corrosion [6-11], with particle size being a key factor in the coating density achieved [12].

Under slurry impingement conditions, coatings are subjected to a highly destructive environment and are degraded as a result of two contributing factors; mechanical wear due to sand particulates within the slurry impacting on the material surface and corrosion from the saline solution [13]. Under these conditions, the degradation process is known as erosion-corrosion. The erosion-corrosion of steel has been widely studied with the effects of erodent size, flow velocity and angle of attack all being documented [14-20]. These studies have shown measurable changes in the electrochemical properties of steel under flowing conditions when contrasted with corresponding properties under static conditions. The observed variation is attributed to particulates within the slurry impinging on the material surface causing rapid removal of the passive layer and resulting in a higher rate of electrochemical charge transfer $[21,22]$. Based on this work, it is widely accepted that combination of liquid impingement and electrochemical corrosion processes yields greater mass loss than is produced from the sum of isolated mechanical wear and isolated corrosion. A third mechanism, incorporating the synergistic effect between erosion and corrosion, 
results in the additional mass loss [23]. This synergy effect leads to erosion-enhanced corrosion and corrosion-enhanced erosion with the total mass loss equating to the sum of these three mechanisms [24].

Existing research on the erosion-corrosion behaviour of multiple HVOF coatings is less comprehensive, with previous work failing to address the combined effect of erosion corrosion on HVOF deposited WC-CoCr, $\mathrm{Cr}_{3} \mathrm{C}_{2}-\mathrm{NiCr}$ or $\mathrm{Al}_{2} \mathrm{O}_{3}$ coatings within an environment replicating in-service conditions. Instead, existing studies isolate the effects of wear and corrosion through sliding wear and static corrosion [8,25-29]. The findings of these investigations highlight the substantial improvement to wear [25-28] and corrosion [8,2729] resistance over uncoated substrate that can be achieved with HVOF coatings. Despite consisting of extensive studies assessing electrochemistry, microstructure and mechanical properties, the investigations fail to account for the effects of synergy and as such do not present comprehensive data on the erosion - corrosion behaviour of HVOF deposited coatings under aqueous, flowing conditions [8,25-27]. One such study to address the effect of slurry erosion was carried out by Goyal et al. [30], who investigated the influence of erodent particle size, impact velocity and slurry concentration on the volume loss of two HVOF deposited coatings. Results indicate tungsten-based coatings provide enhanced slurry erosion protection over the uncoated steel, with alumina-based coatings having comparatively poor resistance to slurry erosion. In spite of thorough analysis, the investigation does not isolate the contributing effects of erosion, corrosion and synergy to the overall volume loss under slurry impingement [30]. Bjordal et al. [31] recorded the effects of synergy in thermally sprayed WC coatings with varying $\mathrm{Cr}$ and Co content. The authors conclude that under highly erosive conditions, the influence of corrosion is less significant with the effects of synergy present in coatings with low corrosion resistance (low Cr content). Finally, there have been numerous studies examining the effect of carbide size 
on the wear performance of HVOF deposited coatings [12,26,32,33], the outcomes of which demonstrate the increase in wear rate with increasing carbide size. The presence of larger carbides causes increased damage to the underlying surfaces with WC-CoCr experiencing low wear due to the coatings comparably small carbide size [12] and high hardness [34].

The present study provides insight on the erosion-corrosion performance of HVOF deposited WC-CoCr, $\mathrm{Cr}_{3} \mathrm{C}_{2}-\mathrm{NiCr}$ and $\mathrm{Al}_{2} \mathrm{O}_{3}$ based coatings under slurry liquid impingement. Through the use of liquid impingement apparatus, results will provide an indication of the three coatings' performance under conditions reflecting a flowing environment. The mass loss as a result of erosion, corrosion and the synergy factor has been calculated for each coating in order to generate comparative data for the relative performance of each coating material under multiple angles of attack. Metallographic analysis was carried out to establish a link between coating properties and the mode of coating degradation through assessment of wear scar damage. This body of work seeks to provide a novel insight on the erosioncorrosion performance of WC- $\mathrm{CoCr}, \mathrm{Cr}_{3} \mathrm{C}_{2}-\mathrm{NiCr}$ and $\mathrm{Al}_{2} \mathrm{O}_{3}$ based coatings under slurry liquid impingement through comparative analysis of the three coatings under consistent flowing erosion - corrosion conditions.

\section{Experimental methods}

\subsection{Materials}

WC-CoCr, $\mathrm{Cr}_{3} \mathrm{C}_{2}-\mathrm{NiCr}$ and $\mathrm{Al}_{2} \mathrm{O}_{3}$ coatings were selected for erosion-corrosion testing, with their specific composition detailed in Table 1. Each material was deposited on EN:10025 S355 JR steel substrate using Praxair JP-5000 HVOF equipment. Coatings were examined in the as-deposited condition. Figure 1 shows a SEM micrograph of each of the three coatings in the as-received condition, with coatings comprised of a generally dense structure with limited porosity. Table 2 highlights the associated properties for the three coatings. Average 
carbide/oxide size and coating thickness were evaluated using light optical microscopy, with a Mitutoyo MVK-G1 micro-hardness tester with a $200 \mathrm{gf}$ load used to evaluate average hardness. A Mitutoyo SV 2000 profilometer provided accurate measurements of the respective surface roughness for each coating.

Table 1

Powder composition [35-37].

\begin{tabular}{llll}
\hline $\begin{array}{l}\text { Coating } \\
\text { Material }\end{array}$ & $\begin{array}{l}\text { Powder } \\
\text { Identification Code }\end{array}$ & Composition (wt.\%) & $\begin{array}{l}\text { Substrate } \\
\text { Material }\end{array}$ \\
\hline WC-CoCr & Woka 3652 & $\begin{array}{l}80.6 \mathrm{~W}-10 \mathrm{Co}-4 \mathrm{Cr}- \\
5.2 \mathrm{C}-0.2 \mathrm{Fe}\end{array}$ & S355 Steel \\
& Woka 7202 & $69.9 \mathrm{Cr}-20 \mathrm{Ni}-9.6 \mathrm{C}-$ & S355 Steel \\
$\mathrm{Cr}_{3} \mathrm{C}_{2}$ & $0.5 \mathrm{Fe}$ & \\
& & $100 \mathrm{Al}_{2} \mathrm{O}_{3}$ & S355 Steel \\
$\mathrm{Al}_{2} \mathrm{O}_{3}$ & Al-1110-HP & & \\
\hline
\end{tabular}

Table 2

Coating properties.

\begin{tabular}{lllll}
\hline Coating & $\begin{array}{l}\text { Thickness } \\
(\mu \mathrm{m})\end{array}$ & $\begin{array}{l}\text { Average Carbide/Oxide } \\
\text { Size }(\mu \mathrm{m})\end{array}$ & $\begin{array}{l}\text { Average } \\
\text { Hardness }(\mathrm{HV})\end{array}$ & $\begin{array}{l}\text { Surface Roughness, } \\
\mathrm{R}_{\mathrm{a}}(\mu \mathrm{m})\end{array}$ \\
\hline Uncoated & $\mathrm{N} / \mathrm{A}$ & $\mathrm{N} / \mathrm{A}$ & 200 & 0.172 \\
$\mathrm{WC}-\mathrm{CoCr}$ & 163 & 1.07 & 1364 & 4.119 \\
$\mathrm{Cr}_{3} \mathrm{C}_{2}-\mathrm{NiCr}$ & 176 & 3.47 & 1006 & 1.855 \\
$\mathrm{Al}_{2} \mathrm{O}_{3}$ & 294 & 2.35 & 1164 & 1.063 \\
\hline
\end{tabular}

\subsection{Slurry erosion-corrosion}

A closed loop jet impingement system, as seen as a schematic in Figure 2, was used to carry out this comparative study, as similar systems have been used extensively by researchers to study the effects of erosion - corrosion on materials under high velocity, sand-containing flow regimes $[14,38-40]$. The benefits of this liquid impingement system include the ability to accurately control the flow velocity, manipulate the impingement angle and vary the quantity of erosive particles within the slurry. The stated variables have been shown to have significant impact on the rate of mass loss experienced by the damaged material $[15,41]$. The main tank contained the slurry solution with pump 1 circulating the solution from the main 
tank up to the jet nozzle. This nozzle had a $4 \mathrm{~mm}$ exit diameter and produced a flow velocity of $23 \mathrm{~m} / \mathrm{s}$. Slurry used throughout the study was comprised of a $3.5 \mathrm{wt} . \% \mathrm{NaCl}$ solution containing FS9 grade angular silica sand with an average particle size of $0.355 \mathrm{~mm}$. The test specimen was located directly beneath the nozzle, whilst fully immersed in the slurry solution. Pump 2 allowed efficient removal of slurry with the system subsequently flushed with fresh water to remove all trace particulates, thereby ensuring consistent sand content throughout all experimental testing. Table 3 highlights the parameters for all liquid impingement tests carried out.

Prior to testing, all specimens were lightly abraded using 500 grit SiC paper, to produce a uniform surface finish and weighed using a mass balance of accuracy $0.1 \mathrm{mg}$. Specimens were weighed prior to, and following testing to determine the total mass loss. The specimen holder was modified to attain mass loss values for both $90^{\circ}$ and $30^{\circ}$ under free erosion-corrosion conditions. Three test replicates for each coating were evaluated in order to calculate an average mass loss value.

\section{Table 3}

Liquid Impingement Test Parameters

\begin{tabular}{lllll}
\hline $\begin{array}{l}\text { Flow Velocity } \\
(\mathrm{m} / \mathrm{s})\end{array}$ & $\begin{array}{l}\text { Sand Concentration } \\
(\mathrm{g} / \mathrm{l})\end{array}$ & $\begin{array}{l}\text { Standoff } \\
\text { Distance }(\mathrm{mm})\end{array}$ & $\begin{array}{l}\text { Test Time } \\
(\mathrm{hr})\end{array}$ & $\begin{array}{l}\text { Sample Diameter } \\
(\mathrm{mm})\end{array}$ \\
\hline 23 & 2.3 & 20 & 1 & 20 \\
\hline
\end{tabular}

\subsection{Electrochemical measurement}

The application of cathodic protection and anodic/cathodic polarization was necessary to isolate the effects of pure erosion and pure corrosion from the total mass loss in order to quantify the influence of synergy. Sample preparation was kept consistent with total mass loss testing, with identical liquid impingement setup used (Figure 2). A WaveNow potentiostat, produced by Pine Instruments, in conjunction with Aftermath data acquisition 
software facilitated the electrochemical analysis. Platinum foil served as the auxiliary electrode with a Double Junction $\mathrm{Ag} / \mathrm{AgCl}$ electrode used as the reference electrode.

Application of cathodic protection enabled calculation of the component of mass loss relating to pure erosion. A potential of $-1 \mathrm{~V}$ was applied across the specimen (working electrode) which supressed any anodic reaction and prevented any corrosion from taking place on the specimen surface.

Mass loss from corrosion was determined through DC anodic/cathodic polarization scans under static and flowing conditions. The $E_{\text {corr }}$ value for each coating type was established for both conditions, with scans conducted for 40 min in order to allow sufficient time for the potential to settle. Static conditions refer to the specimen submerged in $3.5 \%$ $\mathrm{NaCl}$ solution with no liquid impingement acting on the surface. For the polarization scans, the applied potential was swept from $E_{\text {corr }}-250 \mathrm{mV}$ (cathodic) to $E_{\text {corr }}+250 \mathrm{mV}$ (anodic) at a sweep rate of $14 \mathrm{mV} / \mathrm{min}$; this provided sufficient potential range to determine the corrosion current density using Tafel extrapolation from both the cathodic and anodic curves. The calculated values were used to determine the corresponding corrosion mass loss rate using the method outlined in ASTM G102 - 89(2010) [42]. Since the coatings included a mixture of elements, the equivalent weight of each constituent was evaluated using equation 1. Valence values were obtained from published literature [43]. Mass loss rate was calculated using equation 2, incorporating the respective equivalent weight values determined for each coating. The mass loss from corrosion and erosion was subtracted from the total mass loss under free erosion-corrosion conditions to establish the mass loss attributed to the synergistic effect of combined erosion-corrosion. 
Where $E W$ is the equivalent weight, fi represents the mass fraction of the specific element, $n i$ is the valance value of the specific element and $W i$ is the atomic weight of the specific element. $K 2$ is a contestant from Faraday's equation and is equal to $8.954 \times 10^{-3} \mathrm{~g} \mathrm{~cm}^{2} / \mu \mathrm{A}$ $m^{2} d$

\subsection{Surface topography}

Post experimental surface analysis was carried out to evaluate the damage caused by the erosive slurry. This incorporated assessment of specimen topography and wear scar depth. Analysis was performed using an Olympus GX51 light optical microscope that was used to evaluate surface features in detail. A Mitutoyo SV 2000 profilometer provided accurate measurements of wear scar depth. A non-contact optical surface characterisation system (Alicona Infinite Focus G4) facilitated the examination of the wear scar region and determined the volume loss in the directly impinged zone and turbulent zone of the wear scar. In doing so, it was possible to determine the contribution to total volume loss of the direct impinging slurry and the sliding wear in the turbulent region.

\section{Results and discussion}

\subsection{Macro observations}

A typical wear scar for each of the three coatings as well as uncoated S355 was captured using an Alicona optical imaging system; these are highlighted in Figure 4. The specimens exhibit two distinct zones within the impinged area. The central region represents the direct impingement zone and relates to the area of the test specimen located immediately beneath the $4 \mathrm{~mm}$ jet nozzle. The exit diameter of the nozzle correlates to a directly impinged region of $12.6 \mathrm{~mm}^{2}$. The outer zone indicates a turbulent region that experiences significant sliding erosion as particles are forced outwards at high velocity 
following impact in the direct zone. The size variation of the turbulent region between WC-CoCr and $\mathrm{Cr}_{3} \mathrm{C}_{2}$-Nicr is exhibited in Figure 5.

\subsection{Mass loss}

Figure 6 displays the influence of the angle of attack on the free erosion-corrosion mass loss. The average mass loss for each coating type is shown over three test replicates for both $90^{\circ}$ and $30^{\circ}$ angle of attack. Error bars indicate the range of individual test results. It should be noted that the indicated mass loss for $\mathrm{Cr}_{3} \mathrm{C}_{2}-\mathrm{NiCr}$ and $\mathrm{Al}_{2} \mathrm{O}_{3}$ specimens also includes mass loss from the substrate material, due to the coatings being breached within the highly aggressive test conditions.

The results demonstrate that the comparably ductile S355 substrate experiences greater mass loss with a shallower angle of attack. In contrast, the coated specimens exhibit significantly greater mass loss under $90^{\circ}$ angle of attack. This trend is attributed to the presence of hard carbide particles within the coating layer and agrees with the work of [15]. Andrews et al., who previously demonstrated that alloys with higher carbide content experience increased mass loss at greater angles of attack, with more ductile steels experiencing the greatest mass loss at shallower angles of attack [15].

Despite its high hardness, the $\mathrm{Al}_{2} \mathrm{O}_{3}$ coating has experienced significant mass loss under $90^{\circ}$ angle of attack, with the calculated average mass loss being close to that of uncoated $\mathrm{S} 355$. In contrast to impingement at $90^{\circ}$, the $\mathrm{Al}_{2} \mathrm{O}_{3}$ specimen exhibits substantially less mass loss under impingement at $30^{\circ}$. This is in agreement with the reported findings [15] in which the increased quantity of carbides results in maximum damage occurring at higher angles of attack. A similar mechanism exists within the $\mathrm{Cr}_{3} \mathrm{C}_{2}-\mathrm{NiCr}$ specimens, with attack at $90^{\circ}$ causing greater mass loss than the uncoated material. The coating suffered less degradation at $30^{\circ}$, however still proved the poorest performing coating of the three. Reduced mass loss over the $\mathrm{Cr}_{3} \mathrm{C}_{2}-\mathrm{NiCr}$ and $\mathrm{Al}_{2} \mathrm{O}_{3}$ coated specimens demonstrates the ability 
of Cobalt to effectively retain carbide particles within the coating matrix. This, combined with the increased hardness of the coating, has resulted in WC-CoCr functioning as an effective protective layer for $\mathrm{S} 355$ steel under erosion - corrosion conditions at both $90^{\circ}$ and $30^{\circ}$ angles of attack. The findings support previous work on the erosion-corrosion of HVOF coatings under multiple angles of attack $[15,29,44-46]$.

The correlation between mass loss and angle of attack is highlighted in Figure 7. Firstly, there is a link between high average coating hardness, see Table 2, and minimal mass loss. The recorded data shows mass loss to be inversely proportional to coating hardness. This relation is present for both angles of attack and is in agreement with existing findings $[25,47]$. Additionally, Figure 7 highlights the variation in mass loss between $30^{\circ}$ and $90^{\circ}$ angles of attack. In the case of uncoated steel, the lack of ceramic particles yields a comparably ductile structure [48]. Figure 7 demonstrates a negative gradient linking the average mass loss at $30^{\circ}$ and $90^{\circ}$ angles of attack, i.e. the steel experiences increased mass loss at shallower angles of attack. $\mathrm{Al}_{2} \mathrm{O}_{3}$ does not follow this trend due to the coating consisting entirely of a single ceramic phase, hence the lack of binder within the coating matrix results in $\mathrm{Al}_{2} \mathrm{O}_{3}$ retaining the lowest overall ductility. As exhibited in Figure 7 , the $\mathrm{Al}_{2} \mathrm{O}_{3}$ coating displays a steep gradient linking the two impingement angles. The gradient linking the two angles of attack reduces due to the presence of binder in $\mathrm{WC}-\mathrm{CoCr}$ and $\mathrm{Cr}_{3} \mathrm{C}_{2^{-}}$ $\mathrm{NiCr}$, becoming a negative value for steel.

\subsection{Volume loss}

Figure 8 depicts the resulting volume loss within the wear scar, highlighting the volume loss from the coating layer and substrate, for both the directly impinged and turbulent regions. Volume loss in the turbulent region is determined by measuring the 
difference in volume losses between the entire wear scar and the directly impinged region using the Alicona surface analysis system.

The data presents a number of noteworthy trends; $\mathrm{Cr}_{3} \mathrm{C}_{2}-\mathrm{NiCr}$ specimens suffered the greatest loss of material from the specimen substrate, with total volume loss in the direct zone comprising approximately $40 \%$ coating loss and $60 \%$ substrate loss. WC-CoCr is the only coating that has not been penetrated following 1-hour of exposure to the impinging slurry. Without the deep impact crater observed in other specimens, the impinging particles are free to scour across the surface of the WC-CoCr coating, eroding a wider area of material as demonstrated in Figure 5. The total volume loss recorded in WC-CoCr is approximately $20 \%$ of the value recorded for the uncoated material. Both $\mathrm{Cr}_{3} \mathrm{C}_{2}-\mathrm{NiCr}$ and $\mathrm{Al}_{2} \mathrm{O}_{3}$ specimens have sustained substantial damage to the substrate material immediately beneath the directly impinged zone. This has formed a deep crater; increased depth of this crater correlates to the reduced respective volume loss from the turbulent region, with the shallower WC-CoCr wear scar promoting increased sliding erosion in the turbulent zone.

\subsection{Electrochemical measurements}

Electrochemical measurements are necessary to determine the contributing factors of erosion, corrosion and the synergistic effects of both to the total mass loss. Figure 9 illustrates the average mass loss variation between the three coatings under free erosion corrosion conditions and with applied CP.

Erosion-corrosion mass loss experiments show WC-CoCr coatings to yield around $60 \%$ reduction in mass loss with and without applied $\mathrm{CP}$, over the uncoated substrate. Conversely, both $\mathrm{Cr}_{3} \mathrm{C}_{2}-\mathrm{NiCr}$ and $\mathrm{Al}_{2} \mathrm{O}_{3}$ specimens resulted in enhanced mass loss when compared with uncoated S355 substrate. Applied CP has had the most significant impact on 
the uncoated and $\mathrm{Al}_{2} \mathrm{O}_{3}$ specimens, with mass loss of $\mathrm{CP}$ protected specimens measurably less than observed under free erosion - corrosion conditions.

The application of CP necessitated the measurement of OCP for each coating material under both flowing and static conditions. Figure 10a outlines the variation in $\mathrm{E}_{\text {corr }}$ between the three coating types and the uncoated S355 substrate for static conditions, with Figure 10b showing results for flowing conditions.

After $200 \mathrm{~s}$ of exposure to the flowing slurry, the $\mathrm{E}_{\text {corr }}$ values for $\mathrm{Cr}_{3} \mathrm{C}_{2}-\mathrm{NiCr}$ dropped to approximately $-600 \mathrm{mV}$. The proximity of this value to the $E_{\text {corr }}$ of uncoated S355 demonstrates that the coating has been damaged to such an extent that current is able to flow between the slurry and the substrate. Under static conditions, the $\mathrm{Al}_{2} \mathrm{O}_{3}$ coating restricted the flow of current between the slurry and the electrode. As a result, no corrosion density data is presented for this coating in static conditions. When exposed to the impinging slurry, no current flow was detected for $100 \mathrm{~s}$, after which a $-80 \mathrm{mV}$ voltage was measured across the working electrode. Given that the $\mathrm{Al}_{2} \mathrm{O}_{3}$ coating halts the flow of current, the identified voltage is ascribed to the current flowing between the substrate and the slurry. Continued impingement led to an increase in the detected voltage, thus indicating that more of the substrate material has been exposed to the slurry. After $420 \mathrm{~s}$, the $E_{\text {corr }}$ of the specimen fell rapidly to $-480 \mathrm{mV}$ and stayed constant at this value for the remainder of the test. The results demonstrate that following $80 \mathrm{~s}$ of exposure, the impinging jet has damaged the coating sufficiently to allow current flow between the substrate and the slurry. Continued impingement has led to the complete removal of the $\mathrm{Al}_{2} \mathrm{O}_{3}$ layer after $420 \mathrm{~s}$, at which point the $E_{\text {corr }}$ of the specimen dropped to a value similar to that of the uncoated S355 substrate. This further highlights the poor performance of $\mathrm{Al}_{2} \mathrm{O}_{3}$ and $\mathrm{Cr}_{3} \mathrm{C}_{2}-\mathrm{NiCr}$ as protective surface coatings exposed to aggressive slurry erosion. The rapid removal of coating material 
resulted in an inability to generate corrosion rate values under flowing conditions. Thus, the mass loss from pure corrosion under flowing conditions was determined for uncoated S355 and WC-CoCr only. However, the corrosion rate for static conditions was determined for each coating in order to provide some indication as to the corrosion performance of each material. $\mathrm{Al}_{2} \mathrm{O}_{3}$ was excluded from this test as no current was able to flow between the electrode and the slurry under static conditions. Tables 4 and 5 show the extrapolated corrosion density for each material under static and flowing conditions, respectively. The polarization curves for WC-CoCr and uncoated S355 are shown in Figure 11. The large fluctuations in the current density are indicative of particle impingement, which caused disruption of the passive layer.

Table 4

Calculated corrosion density for coating material under static conditions.

\begin{tabular}{llll}
\hline & Uncoated & WC-CoCr & $\mathrm{Cr}_{3} \mathrm{C}_{2}-\mathrm{NiCr}$ \\
\hline Total Anodic Current $(\mu \mathrm{A})$ & 47.89 & 6.22 & 1.76 \\
Specimen Area $\left(\mathrm{cm}^{2}\right)$ & 3.14 & 3.14 & 3.14 \\
Current Density $\left(\mu \mathrm{A} / \mathrm{cm}^{2}\right)$ & 15.25 & 1.98 & 0.56 \\
\hline
\end{tabular}

Table 5

Calculated corrosion density for coating material under flowing conditions.

\begin{tabular}{lll}
\hline & Uncoated & WC-CoCr \\
\hline Total Anodic Current $(\mu \mathrm{A})$ & 2331.64 & 44.65 \\
Specimen Area $\left(\mathrm{cm}^{2}\right)$ & 3.14 & 3.14 \\
Current Density $\left(\mu \mathrm{A} / \mathrm{cm}^{2}\right)$ & 742.53 & 14.22 \\
\hline
\end{tabular}

Polarization sweeps reveal significant variance in the corrosion rate, for each of the three coatings - as seen in Tables 4 and 5. The results show $\mathrm{Cr}_{3} \mathrm{C}_{2}-\mathrm{NiCr}$ to display a significantly lower corrosion rate compared with all assesed coatings. The method outlined in ASTM G102 - 89(2010) [42,43] was employed to calculate hourly mass loss rates for each coating material from the extrapolated current density. Table 6 shows the contribution of 
each wear mechanism to the total mass loss under flowing, free erosion - corrosion conditions. It is clear that mass loss within flowing liquid impingement environment is highly erosion dominant, with the synergistic effect of combined corrosion and erosion contributing around $10 \%$ of the total mass loss in the case of uncoated S355.

$\mathrm{Cr}_{3} \mathrm{C}_{2}-\mathrm{NiCr}$ provides excellent corrosion resistance; however, due to the comparatively poor performance when exposed to the impinging jet, the coating has not provided suitable protection under erosive conditions. While not as corrosion resistant as $\mathrm{Cr}_{3} \mathrm{C}_{2}-\mathrm{NiCr}$, WC-CoCr presents a substantial reduction in current density for flowing and static conditions over the uncoated specimen. This, in combination with high resiatance to erosive wear, results in the WC-CoCr coating providing exceptional protection of the S355 substrate under flowing erosion-corrosion conditions.

Table 6

Percentage contribution of pure erosion, pure corrosion and synergy to total mass loss under flowing conditions.

\begin{tabular}{lllll}
\hline Coating Material & Total Mass Loss (\%) & Erosion (\%) & Corrosion (\%) & Synergy (\%) \\
\hline Uncoated & 100 & 83.9 & 4.97 & 11.13 \\
WC-CoCr & 100 & 87.0 & 0.19 & 12.81 \\
\hline
\end{tabular}

\subsection{Post-test characterization}

\subsubsection{Macro examination of eroded surfaces}

The typical wear scar for each of the three coatings and the uncoated S355 was captured using an Alicona optical imaging system and is highlighted in Figure 4. Figure 12 depicts a comparative analysis of the wear scar depths from each coating material following 1-hour free erosion - corrosion impingement, measured using a surface profilometer. Wear scar depth was corroborated using an Alicona with results being shown in Table 7. It is evident that the $\mathrm{Al}_{2} \mathrm{O}_{3}$ coating has developed the largest wear scar, with a maximum 
recorded depth of $678 \mu \mathrm{m}$. The scar depth for $\mathrm{Cr}_{3} \mathrm{C}_{2}-\mathrm{NiCr}$ was shown to be marginally shallower, however, given the comparably thin coating layer, the substrate penetration depth is $100 \mu \mathrm{m}$ greater than in the $\mathrm{Al}_{2} \mathrm{O}_{3}$. The recorded maximum wear scar depth for WCCoCr was $141.7 \mu \mathrm{m}$. With an indicated coating thickness of $180 \mu \mathrm{m}$, the results verify that the coating layer has not been breached following the 1-hour liquid impingement test. The significant reduction in wear scar depth clearly demonstrates that WC-CoCr has provided superior protection of the S355 substrate over other assessed coatings.

Table 7

Wear scar properties

\begin{tabular}{lllll}
\hline Coating & $\begin{array}{l}\text { Coating } \\
\text { Thickness } \\
(\mathrm{mm})\end{array}$ & $\begin{array}{l}\text { Profilometer Indicated } \\
\text { Scar Depth }(\mu \mathrm{m})\end{array}$ & $\begin{array}{l}\text { Alicona } \\
\text { Indicated Scar } \\
\text { Depth }(\mu \mathrm{m})\end{array}$ & $\begin{array}{l}\text { Average Substrate } \\
\text { Penetration Depth } \\
(\mu \mathrm{m})\end{array}$ \\
\hline Uncoated & N/A & 518.9 & 518.5 & 518 \\
WC-CoCr & 163 & 145.9 & 141.7 & 0 \\
$\mathrm{Cr}_{3} \mathrm{C}_{2}-\mathrm{NiCr}$ & 176 & 657.0 & 653.7 & 481 \\
$\mathrm{Al}_{2} \mathrm{O}_{3}$ & 294 & 680.0 & 678.0 & 386 \\
\hline
\end{tabular}

Both the $\mathrm{Cr}_{3} \mathrm{C}_{2}-\mathrm{NiCr}$ and uncoated specimens exhibited similar wear scars, with $\mathrm{Cr}_{3} \mathrm{C}_{2}-\mathrm{NiCr}$ developing a scar of marginally greater depth. Wear scar analysis indicates the deleterious effects of $\mathrm{Cr}_{3} \mathrm{C}_{2}-\mathrm{NiCr}$ and $\mathrm{Al}_{2} \mathrm{O}_{3}$ coating on $\mathrm{S} 355$ substrate. In both instances, the presence of a coating increased the total mass loss and enlarged the produced wear scar. This phenomenon has been attributed to the erosive effects of coating particulates previously removed by the impinging slurry acting as a secondary erodent.

\subsubsection{Microstructural characterisation}

Light optical microscopy, operating in dark field mode, facilitated further evaluation of the associated wear mechanisms operating in the two mentioned zones. The use of dark field improved image contrast and proved more effective at revealing signs of damage in 
each region. The examined specimens had been subjected to 1-hour free erosion - corrosion tests at $90^{\circ}$ angle of attack.

Figure 13a reveals enhanced surface roughness within the central impinged zone. Uncoated S355 shows evidence of wear marks in the form of microcutting and ploughing. Moreover, there exist small craters on the damaged surface caused by impinging sand particles. A similar result was noted by Santa et al. [49], who related increasing size of impact craters to increased impinging particle size. The production of craters on the surface leads to the presence of crater lips that are subsequently removed by the cutting motion of the particles as the move out from the centre of the directly impinged zone. The cause of material loss is therefore associated with repetitive plastic deformation caused by impinging particles followed by microcutting. Figure $13 \mathrm{~b}$ highlights the directionality in the turbulent zone, with evidence of parallel scratch patterns and apparent microcutting [30].

Figure 14a illustrates the damage to the $\mathrm{Cr}_{3} \mathrm{C}_{2}-\mathrm{NiCr}$ coated specimen within the outer turbulent region. Complete coating removal in the directly impinged zone results in a surface similar to that observed in Figure 13a. Examination of the turbulent zone reveals signs of directionality in the orientation of surface damage. It is therefore expected that the majority of erosive wear has been contained within the wear scar crater. However, as particles move outwards from the crater, they slide and graze across the surface of the coating resulting in the observed damage. Within the turbulent zone, there also exist signs of particle removal. The ability for particles to be pulled out of the coating matrix accelerates material removal by acting as an additional erodent and supports the high mass loss experienced by the $\mathrm{Cr}_{3} \mathrm{C}_{2^{-}}$ $\mathrm{NiCr}$ coated specimens.

The structure of $\mathrm{Al}_{2} \mathrm{O}_{3}$ presents different characteristics from the previous two coatings. The pure ceramic coating is highly brittle and possesses no ductile binder. Thus, 
material loss occurs rapidly with $\mathrm{Al}_{2} \mathrm{O}_{3}$ particles spalling off. Owing to complete coating removal within the directly impinged zone, the structure in this region reflects the structure of Figure 13a. Figure 14b highlights the apparent directionality in the turbulent region surrounding the directly impinged zone. The lack of binder material has resulted in rapid removal of the protective $\mathrm{Al}_{2} \mathrm{O}_{3}$ coating with removed alumina particles causing further damage to the exposed S355 substrate. This contributes to the enhanced mass and volume loss over uncoated S355.

Micrographs of the central impinged and turbulent zones within the WC-CoCr coating are depicted in Figure 15 and reveal a wear mechanism similar to that observed in uncoated S355. There is evidence of impact craters within the directly impinged zone. The presence of craters indicates the surrounding material has retained its structure following impact. With continued liquid impingement, carbide particles fracture and cannot be retained by the cobalt matrix, with continuous flow eventually removing the particles from the coating matrix altogether. Corroborating results have been obtained by Thakur et al. [34] . The remaining cobalt binder has insufficient hardness to withstand the erosive conditions and is eventually removed. Microcutting is also evident and is linked to the ploughing of silica particles and removal of soft cobalt binder. The observations are in accordance with those reported in associated studies $[50,51]$. The superior wear performance of the WC-CoCr coating can be attributed to the cobalt binder effectively retaining the hard carbide particles within the matrix. The turbulent zone shown in Figure 15b depicts some signs of directionality but in contrast with other specimens, shows signs of more erratic wear. This is to be expected given the lack of a defined impact crater. 


\section{Conclusions}

The novel research work undertaken in the present study has evaluated HVOF deposited WC-CoCr, $\mathrm{Cr}_{3} \mathrm{C}_{2}-\mathrm{NiCr}$ and $\mathrm{Al}_{2} \mathrm{O}_{3}$ surface coatings on $\mathrm{S} 355$ steel. Specimens were subjected to highly erosive liquid impingement testing, with resultant mass and volume loss calculated for each coating material. The scope of the study has incorporated electrochemical assessment to determine the effect of combined corrosion and erosion as well as metallographic analysis to evaluate the mechanisms causing coating degradation. The following outlines the conclusions drawn from this body of work.

- Electrochemical analysis confirmed a highly erosion dominant wear regime, with pure corrosion contributing no more than $6 \%$ to the total mass loss in the case of uncoated 355 . Under flowing conditions, pure corrosion contributed only $0.34 \%$ to the mass loss of WC-CoCr coated specimens.

- The pull-out of carbides from the coating layer acts as an additional erodent within the slurry leading to enhanced mass and volume loss over uncoated S355. The damage resulting from carbide pull-out is highly dependent on the respective carbide size. In this context, the high mass loss associated with $\mathrm{Cr}_{3} \mathrm{C}_{2}-\mathrm{NiCr}$ coatings can be partly attributed to the large carbide size.

- Wear scar analysis has shown substantial variation in material loss experienced by the three coatings. In the case of WC-CoCr, the wear scar is shallower with the impinging slurry unable to penetrate through to the substrate material in the prescribed test duration.

- $\mathrm{Al}_{2} \mathrm{O}_{3}$ coatings provide comparably poor protection under erosion - corrosion conditions. The large particle size, in conjunction with the lack of ductile supporting binder, results in enhanced mass loss over uncoated S355 and significant increase to 
the depth of wear scar. The lack of ductile binder resulted in the rapid removal of alumina particles, which in turn acted as a secondary erosive medium within the slurry, resulting in enhanced mass loss.

- Despite $\mathrm{Cr}_{3} \mathrm{C}_{2}-\mathrm{NiCr}$ providing substantial corrosion resistance, as demonstrated through calculation of static corrosion rate, the coating failed to withstand the effects of erosive wear under liquid impingement conditions. This resulted in the highest observed mass loss out of all examined specimens, with a value $52 \%$ greater than uncoated material. Post-test volumetric analysis also revealed the $\mathrm{Cr}_{3} \mathrm{C}_{2}-\mathrm{NiCr}$ coated specimen to have the highest percentage of total volume loss attributed to substrate material loss.

- WC-CoCr provides enhanced protection over uncoated S355 substrate. Total mass loss was reduced by $61 \%$ with wear scar depth reducing by $56 \%$. The low mass loss and minimal wear scar can be attributed to high hardness and the ability of the cobalt matrix to retain the comparably small carbides resulting in a coating layer resistant to the erosive effects of the slurry. The electrochemical properties of the same coating also demonstrate significant resistance to the corrosive effects of the slurry over uncoated S355.

\section{References}

[1] J. Madadnia, J. Kusnan, Analysis of Severe Erosion in Industrial Centrifugal Slurry Pumps, in: Proc. ASME 2013 Fluids Eng. Div. Summer Meet., Nevada, 2013: pp. 1-7.

[2] C.I. Walker, Slurry pump side-liner wear: Comparison of some laboratory and field results, Wear. 250-251 (2001) 81-87.

[3] C.I. Walker, P. Robbie, Comparison of some laboratory wear tests and field wear in slurry pumps, Wear. 302 (2013) 1026-1034.

[4] K. Sugiyama, S. Nakahama, S. Hattori, K. Nakano, Slurry wear and cavitation erosion of thermal-sprayed cermets, Wear. 258 (2005) 768-775.

[5] C.J. Li, G.J. Yang, Relationships between feedstock structure, particle parameter, coating deposition, microstructure and properties for thermally sprayed conventional and nanostructured WC-Co, Int. J. Refract. Met. Hard Mater. 39 (2013) 2-17. 
[6] A. Ibrahim, C.C. Berndt, Fatigue and deformation of HVOF sprayed WC-Co coatings and hard chrome plating, Mater. Sci. Eng. A. 456 (2007) 114-119.

[7] G. Bolelli, L. Lusvarghi, M. Barletta, HVOF-sprayed WC-CoCr coatings on Al alloy: Effect of the coating thickness on the tribological properties, Wear. 267 (2009) 944-953.

[8] G. Bolelli, R. Giovanardi, L. Lusvarghi, T. Manfredini, Corrosion resistance of HVOF-sprayed coatings for hard chrome replacement, Corros. Sci. 48 (2006) 3375-3397.

[9] J.R. García, J.E. Fernández, J.M. Cuetos, F.G. Costales, Fatigue effect of WC coatings thermal sprayed by HVOF and laser treated, on medium carbon steel, Eng. Fail. Anal. 18 (2011) 17501760.

[10] J.G. La Barbera-Sosa, Y.Y. Santana, C. Villalobos-Gutiérrez, D. Chicot, J. Lesage, X. Decoopman, et al., Fatigue behavior of a structural steel coated with a WC-10Co-4Cr/Colmonoy 88 deposit by HVOF thermal spraying, Surf. Coatings Technol. 220 (2013) 248-256.

[11] S. Matthews, B. James, M. Hyland, The role of microstructure in the mechanism of high velocity erosion of $\mathrm{Cr} 3 \mathrm{C} 2-\mathrm{NiCr}$ thermal spray coatings: Part 1 - As-sprayed coatings, Surf. Coatings Technol. 203 (2009) 1086-1093.

[12] P. Chivavibul, M. Watanabe, S. Kuroda, J. Kawakita, M. Komatsu, K. Sato, et al., Effect of powder characteristics on properties of warm-sprayed WC-Co coatings, J. Therm. Spray Technol. 19 (2010) 81-88.

[13] V.A.D. Souza, A. Neville, Corrosion and synergy in a WC-Co-Cr HVOF thermal spray coating Understanding their role in erosion-corrosion degradation, Wear. 259 (2005) 171-180.

[14] Y. Zhao, F. Zhou, J. Yao, S. Dong, N. Li, Erosion-corrosion behavior and corrosion resistance of AISI 316 stainless steel in flow jet impingement, Wear. 328-329 (2015) 464-474.

[15] N. Andrews, L. Giourntas, A.M. Galloway, A. Pearson, Effect of impact angle on the slurry erosion-corrosion of Stellite 6 and SS316, Wear. 320 (2014) 143-151.

[16] M.S. Jellesen, T.L. Christiansen, L.R. Hilbert, P. Møller, Erosion-corrosion and corrosion properties of DLC coated low temperature gas-nitrided austenitic stainless steel, Wear. 267 (2009) 1709-1714.

[17] F. Mohammadi, J. Luo, Effects of particle angular velocity and friction force on erosion enhanced corrosion of 304 stainless steel, Corros. Sci. 52 (2010) 2994-3001.

[18] D. López, N.A. Falleiros, A.P. Tschiptschin, Corrosion-erosion behaviour of austenitic and martensitic high nitrogen stainless steels, Wear. 263 (2007) 347-354.

[19] S. Aribo, R. Barker, X. Hu, A. Neville, Erosion-corrosion behaviour of lean duplex stainless steels in 3.5\% NaCl solution, Wear. 302 (2013) 1602-1608.

[20] M.A. Islam, T. Alam, Z.N. Farhat, A. Mohamed, A. Alfantazi, Effect of microstructure on the erosion behavior of carbon steel, Wear. 332-333 (2015) 1080-1089.

[21] A. Neville, T. Hodgkiess, J.T. Dallas, A study of the erosion-corrosion behaviour of engineering steels for marine pumping applications, Wear. 186-187 (1995) 497-507.

[22] D. Landolt, Corrosion and surface chemistry of metals, 2007.

[23] R. Malka, S. Nešić, D.A. Gulino, Erosion-corrosion and synergistic effects in disturbed liquidparticle flow, Wear. 262 (2007) 791-799.

[24] H. Xu, A. Neville, An electrochemical and microstructural assessment of erosion-corrosion of austenitic cast iron for marine applications, Mater. Corros. 53 (2002) 5-12.

[25] A.J. Gant, M.G. Gee, Wear modes in slurry jet erosion of tungsten carbide hardmetals: Their relationship with microstructure and mechanical properties, Int. J. Refract. Met. Hard Mater. 49 (2015) 192-202.

[26] L. Thakur, N. Arora, R. Jayaganthan, R. Sood, An investigation on erosion behavior of HVOF 
sprayed WC-CoCr coatings, Appl. Surf. Sci. 258 (2011) 1225-1234.

[27] W. Liu, F. Shieu, W. Hsiao, Enhancement of wear and corrosion resistance of iron-based hard coatings deposited by high-velocity oxygen fuel (HVOF) thermal spraying, Surf. Coat. Technol. 249 (2014) 24-41.

[28] Shabana, M.M.M. Sarcar, K.N.S. Suman, S. Kamaluddin, Tribological and Corrosion behavior of HVOF Sprayed WC-Co, NiCrBSi and $\mathrm{Cr} 3 \mathrm{C} 2-\mathrm{NiCr}$ Coatings and analysis using Design of Experiments, Mater. Today Proc. 2 (2015) 2654-2665.

[29] Z.B. Zheng, Y.G. Zheng, W.H. Sun, J.Q. Wang, Erosion-corrosion of HVOF-sprayed Fe-based amorphous metallic coating under impingement by a sand-containing $\mathrm{NaCl}$ solution, Corros. Sci. 76 (2013) 337-347.

[30] D. Kumar Goyal, H. Singh, H. Kumar, V. Sahni, Slurry erosion behaviour of HVOF sprayed WC$10 \mathrm{Co}-4 \mathrm{Cr}$ and $\mathrm{Al} 2 \mathrm{O} 3+13 \mathrm{TiO} 2$ coatings on a turbine steel, Wear. 289 (2012) 46-57.

[31] M. Bjordal, E. Bardal, T. Rogne, T.G. Eggen, Combined erosion and corrosion of thermal sprayed WC and CrC coatings, Surf. Coatings Technol. 70 (1995) 215-220.

[32] Q. Yang, T. Senda, A. Ohmori, Effect of carbide grain size on microstructure and sliding wear behavior of HVOF-sprayed WC-12\% Co coatings, Wear. 254 (2003) 23-34.

[33] P. Chivavibul, M. Watanabe, S. Kuroda, K. Shinoda, Effects of carbide size and Co content on the microstructure and mechanical properties of HVOF-sprayed WC-Co coatings, Surf. Coatings Technol. 202 (2007) 509-521.

[34] L. Thakur, N. Arora, A comparative study on slurry and dry erosion behaviour of HVOF sprayed WC-CoCr coatings, Wear. 303 (2013) 405-411.

[35] Oerlikon Metco, Material Product Data Sheet Tungsten Carbide - $10 \%$ Cobalt $4 \%$ Chromium Powders, (2015) 1-7.

[36] Oerlikon Metco, Material Product Data Sheet Chromium Carbide - Nickel Chromium Powder Blends, 2 (2014) 2-7.

[37] Praxair, Materials Product Data Sheet Al-1110-HP, (1999) 1-4.

[38] L. Giourntas, T. Hodgkiess, A.M. Galloway, Comparative study of erosion-corrosion performance on a range of stainless steels, Wear. 332-333 (2015) 1051-1058.

[39] M.M. Stack, G.H. Abdulrahman, Mapping erosion-corrosion of carbon steel in oil-water solutions: Effects of velocity and applied potential, Wear. 274-275 (2012) 401-413.

[40] M. Abedini, H.M. Ghasemi, Synergistic erosion-corrosion behavior of Al-brass alloy at various impingement angles, Wear. 319 (2014) 49-55.

[41] X. Jiang, Y.G. Zheng, W. Ke, Effect of flow velocity and entrained sand on inhibition performances of two inhibitors for $\mathrm{CO} 2$ corrosion of $\mathrm{N} 80$ steel in $3 \% \mathrm{NaCl}$ solution, Corros. Sci. 47 (2005) 2636-2658.

[42] I. Astm, ASTM G102 - 89 Standard Practice for Calculation of Corrosion Rates and Related Information from Electrochemical Measurements, 2015.

[43] M. Pourbaix, Atlas of Electrochemical Equilibria in Aqueous Solutions, 1974.

[44] R.G. Wellman, C. Allen, The effects of angle of impact and material properties on the erosion rates of ceramics, Fuel Energy Abstr. 37 (1996) 213.

[45] Y. Purandare, M. Stack, P. Hovsepian, A study of the erosion-corrosion of PVD CrN/NbN superlattice coatings in aqueous slurries, Wear. 259 (2005) 256-262.

[46] Y.I. Oka, H. Ohnogi, T. Hosokawa, M. Matsumura, The impact angle dependence of erosion damage caused by solid particle impact, Wear. 203-204 (1997) 573-579.

[47] H.S. Grewal, H. Singh, A. Agrawal, Understanding Liquid Impingement erosion behaviour of nickel-alumina based thermal spray coatings, Wear. 301 (2013) 424-433. 
[48] A.J. Ninham, A. V Levy, The erosion of carbide-metal composites, Wear. 121 (1988) 347-361.

[49] J.F. Santa, J.C. Baena, a. Toro, Slurry erosion of thermal spray coatings and stainless steels for hydraulic machinery, Wear. 263 (2007) 258-264.

[50] V. Fervel, B. Normand, H. Liao, C. Coddet, E. Beche, R. Berjoan, Friction and wear mechanisms of thermally sprayed ceramic and cermet coatings, Surf. Coatings Technol. 111 (1999) 255262.

[51] C. Verdon, A. Karimi, J.L. Martin, Microstructural and analytical study of thermally sprayed WC-Co coatings in connection with their wear resistance, Mater. Sci. Eng. A. 234-236 (1997) 731-734. 
Fig 1. SEM images of HVOF deposited coatings in the as-received condition. a) WC-CoCr, b) $\left.\mathrm{Cr}_{3} \mathrm{C}_{2}-\mathrm{NiCr}, \mathrm{c}\right)$ $\mathrm{Al}_{2} \mathrm{O}_{3}$.

Fig 2. Schematic diagram of recirculating liquid impingement test rig (not to scale). (1) Data logging; (2) Potentiostat; (3) Working electrode; (4) Reference electrode; (5) Auxiliary electrode; (6) Recirculating pump (pump 1); (7) Sample holder; (8) Jet impingement nozzle; (9) Specimen; (10) Slurry solution; (11) Slurry tank; (12) Drainage valve; (13) Drainage pump (pump 2).

Fig 3. Jet nozzle and specimen in situ for liquid impingement at a) $90^{\circ}$ angle of attack, b) $30^{\circ}$ angle of attack.

Fig 4. Macro images of a) Uncoated specimen, b) WC-CoCr, c) $\mathrm{Al}_{2} \mathrm{O}_{3}$, d) $\mathrm{Cr}_{3} \mathrm{C}_{2}-\mathrm{NiCr}$ following erosion-corrosion testing for 1 hour.

Fig 5. Variation in the diameter of the turbulent region between (a) WC-CoCr and (b) $\mathrm{Cr}_{3} \mathrm{C}_{2}-\mathrm{NiCr}$ wear scars.

Fig 6. Mass loss under free erosion-corrosion conditions at $90^{\circ}$ and $30^{\circ}$ angle of attack.

Fig 7. Correlation between angle of attack and total mass loss for each coating type.

Fig 8. Volume loss in direct and turbulent regions following 1 hour liquid impingement test and $90^{\circ}$ angle of attack.

Fig 9. Mass loss of HVOF deposited coatings under free erosion - corrosion conditions and with applied CP.

Fig 10. a) $E_{\text {corr }}$ values under static conditions, b) $E_{\text {corr }}$ values under flowing conditions.

Fig 11. Anodic polarization sweeps of a) Uncoated, b) WC-CoCr, specimens under flowing liquid impingement conditions.

Fig 12. Wear scar depth profiles for three coating material and uncoated substrate following 1-hour free erosion - corrosion test.

Fig 13. Optical image of uncoated specimen following free erosion-corrosion test. a) Directly impinged zone, b) turbulent zone [x100, Unetched].

Fig 14. Turbulent zone of a) $\mathrm{Cr}_{3} \mathrm{C}_{2}-\mathrm{NiCr}$ and b) $\mathrm{Al}_{2} \mathrm{O}_{3}$ coated specimen following free erosion-corrosion test. [x100, Unetched].

Fig 15. Optical image of WC-CoCr coated specimen following free erosion-corrosion test. a) directly impinged region, b) turbulent region $[x 100$, Unetched]. 
Click here to download high resolution image

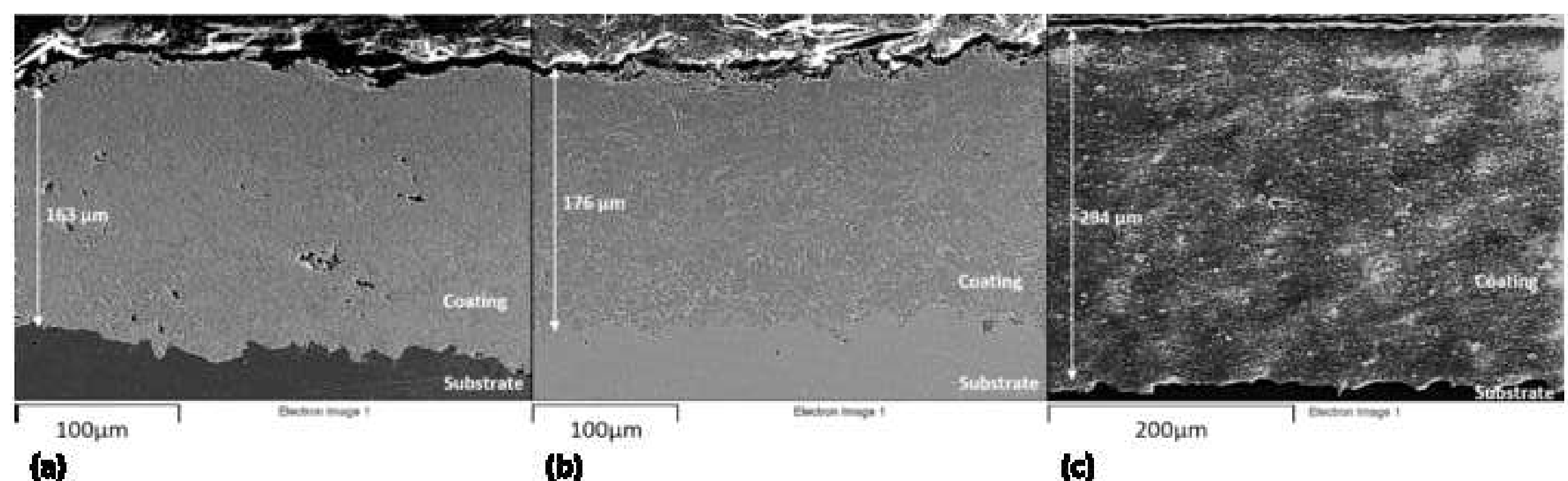

\section{Click here to download high resolution image}

(a)

(b)

(c) 


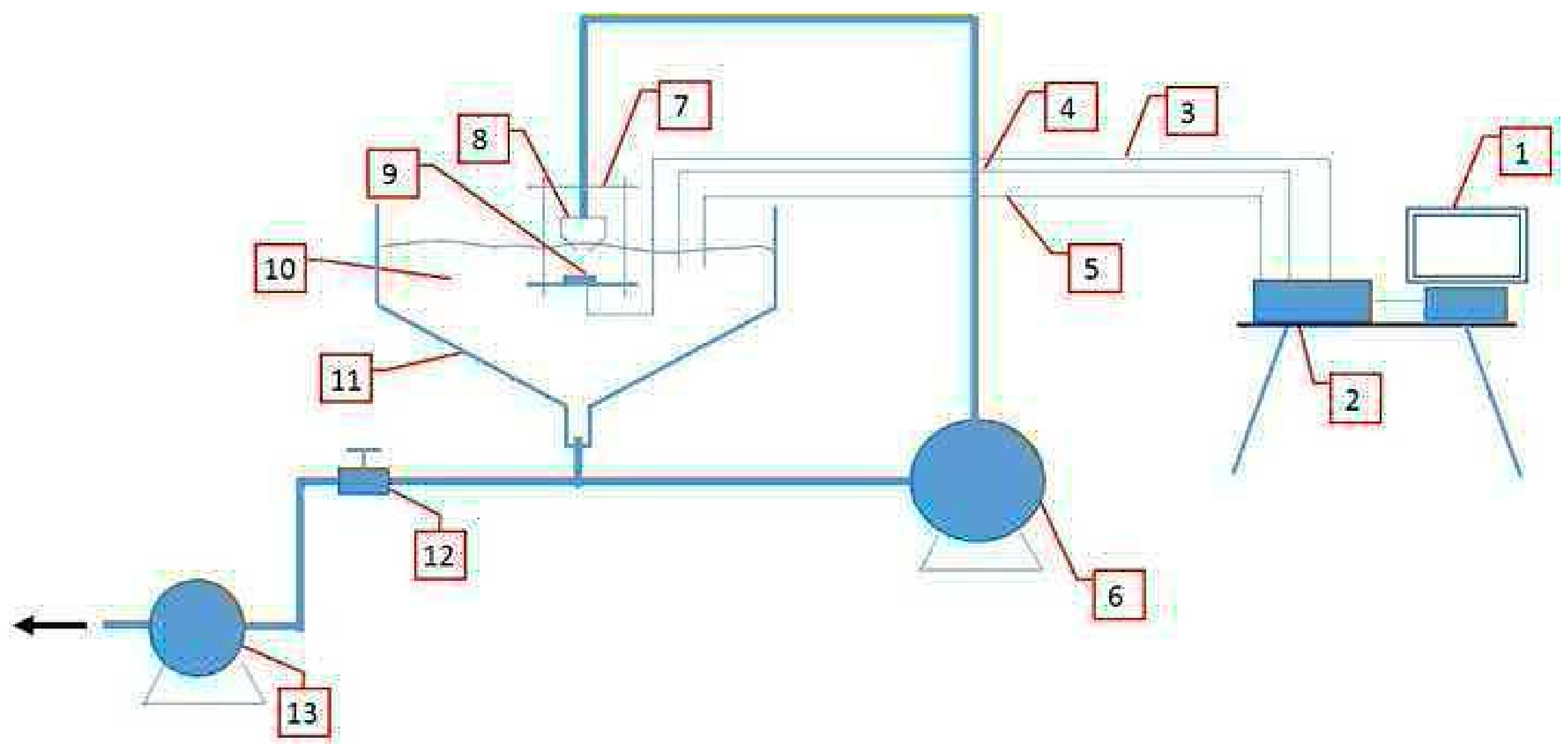


Click here to download high resolution image
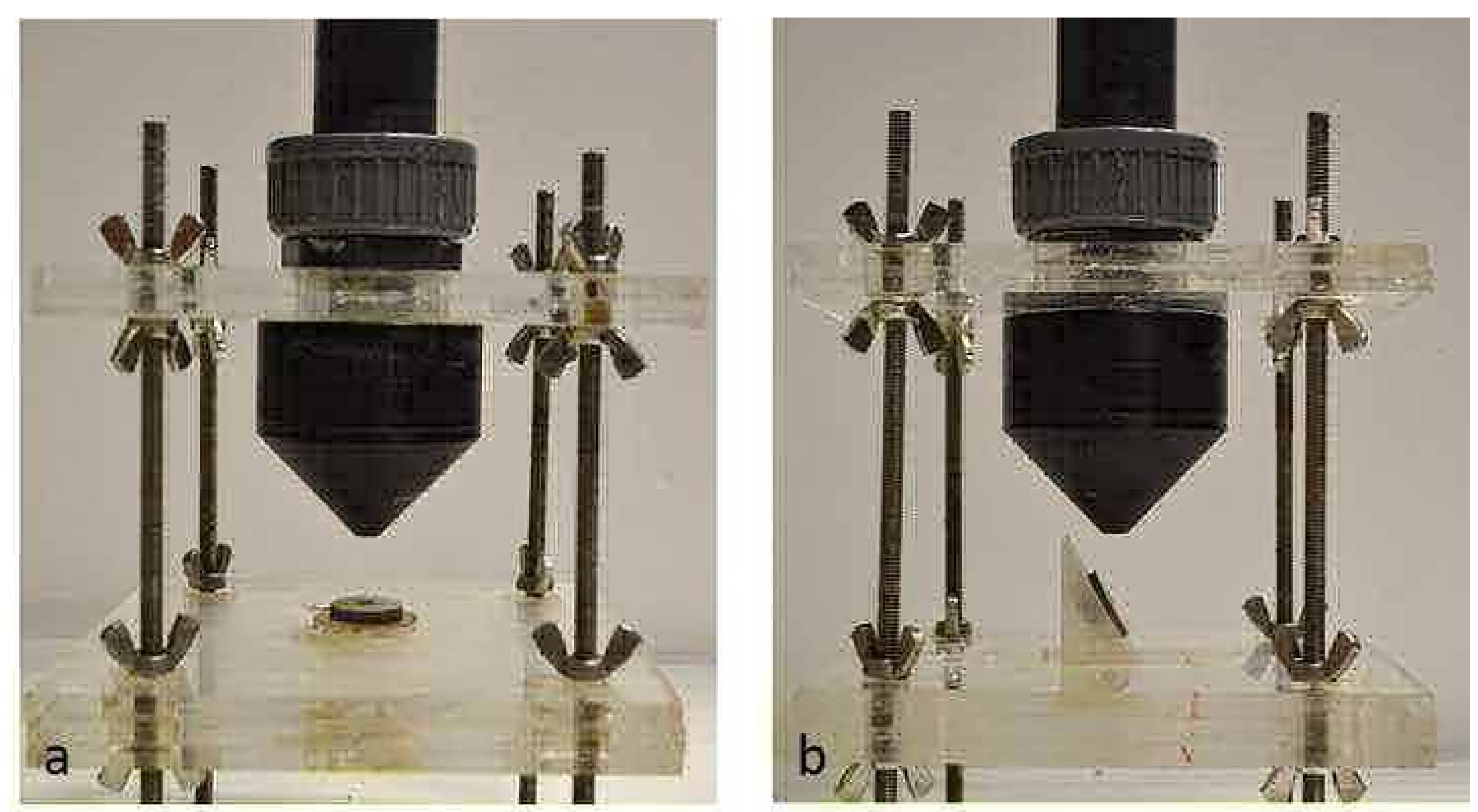
Click here to download high resolution image

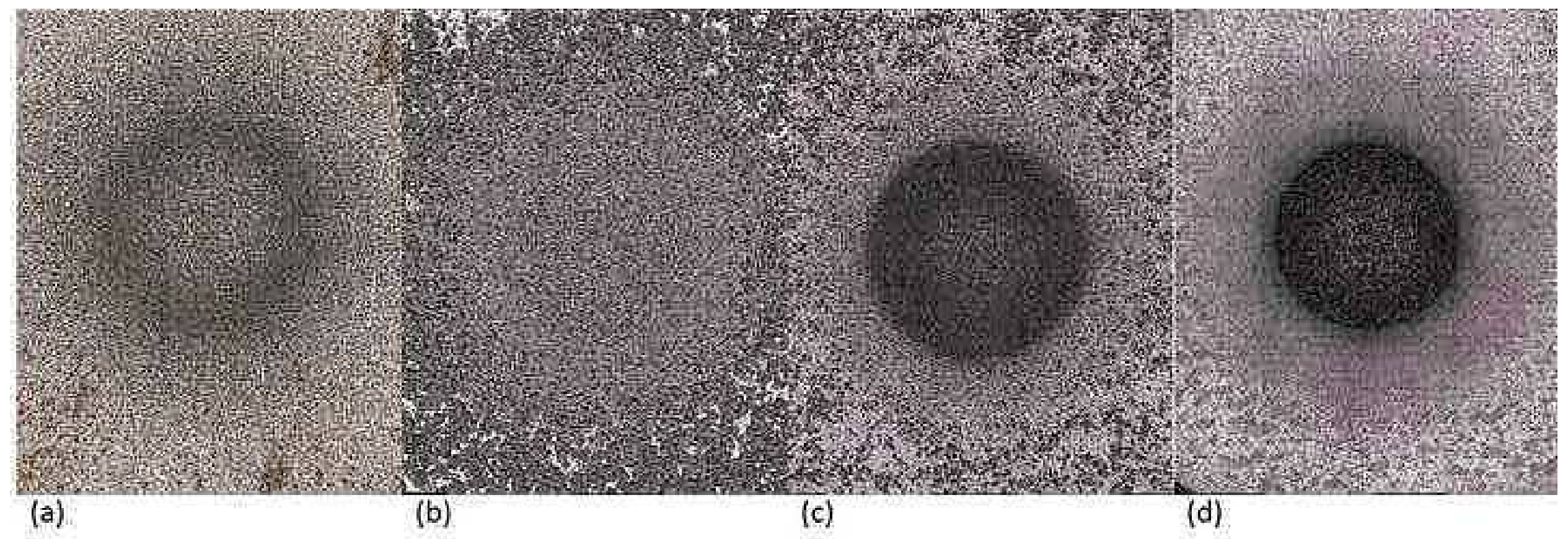


Click here to download high resolution image

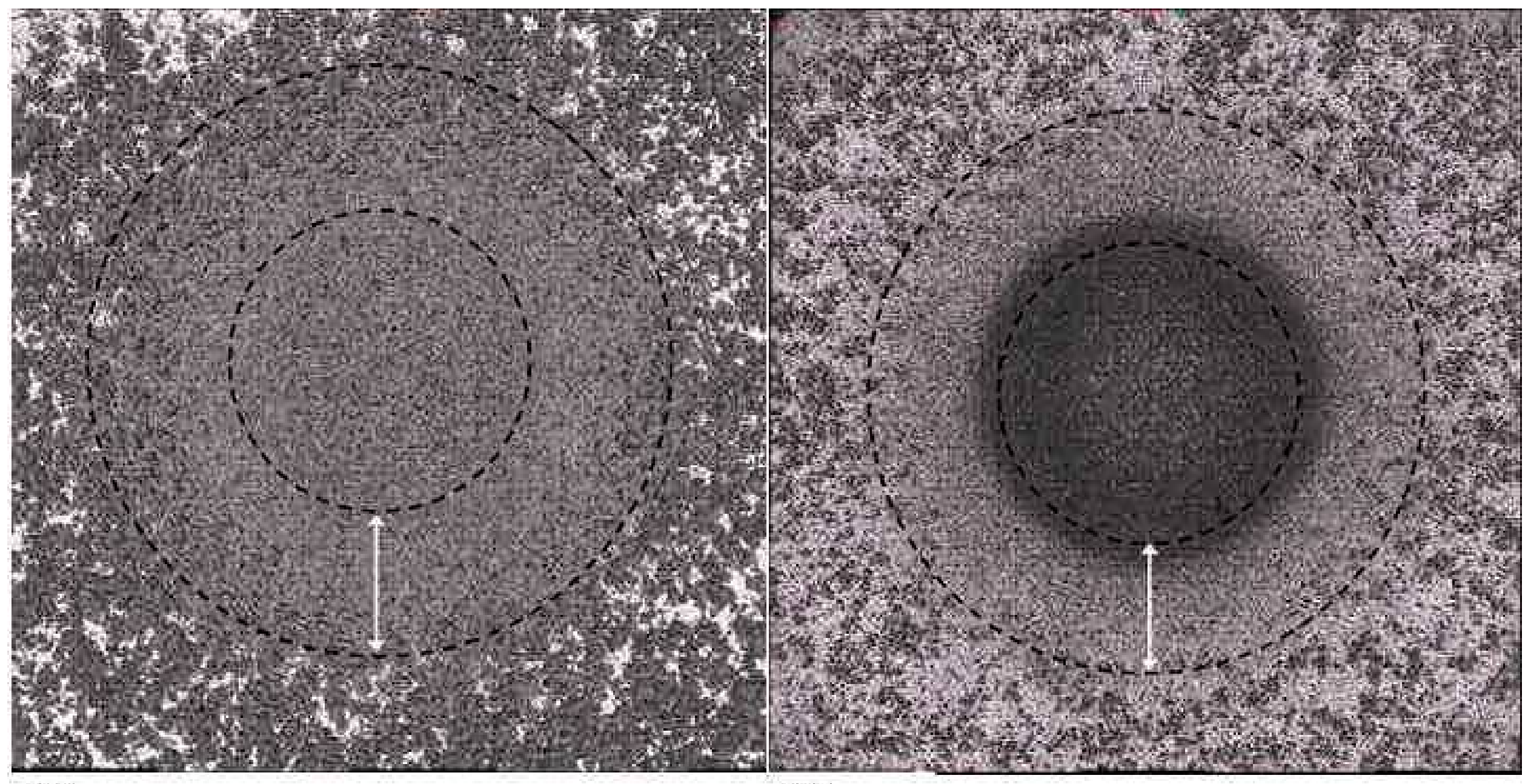

(a)

(b)

(w)

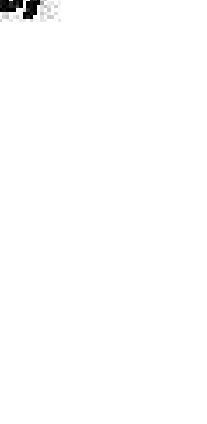




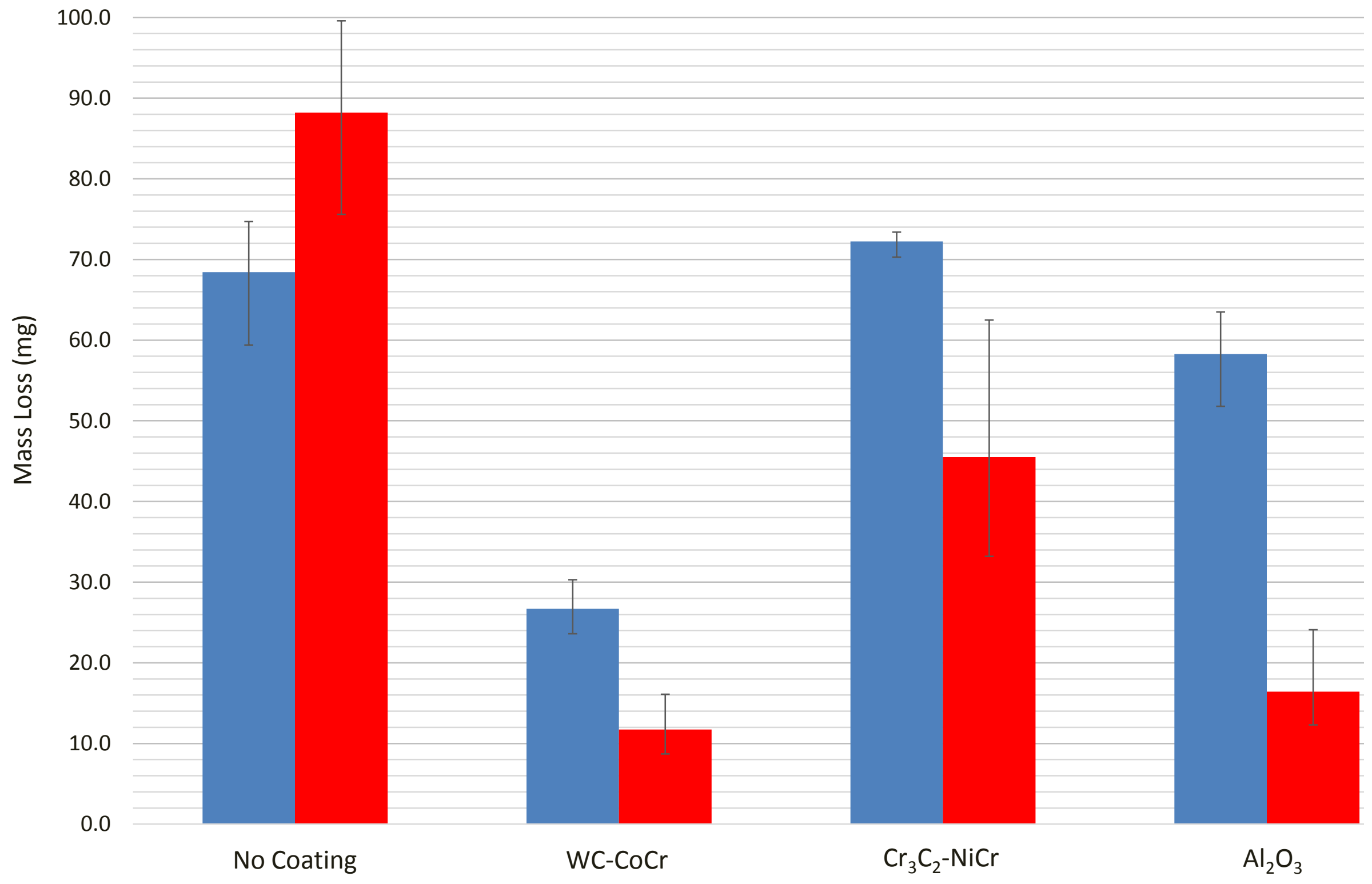


Click here to download Figure: FIG7.xIsx

$$
\begin{array}{ll}
\rightarrow \text { Uncoated S355 } & \rightarrow \text { WC-CoCr } \\
\rightarrow \mathrm{Cr}_{3} \mathrm{C}_{2}-\mathrm{NiCr} & \rightarrow \mathrm{Al}_{2} \mathrm{O}_{3}
\end{array}
$$

100

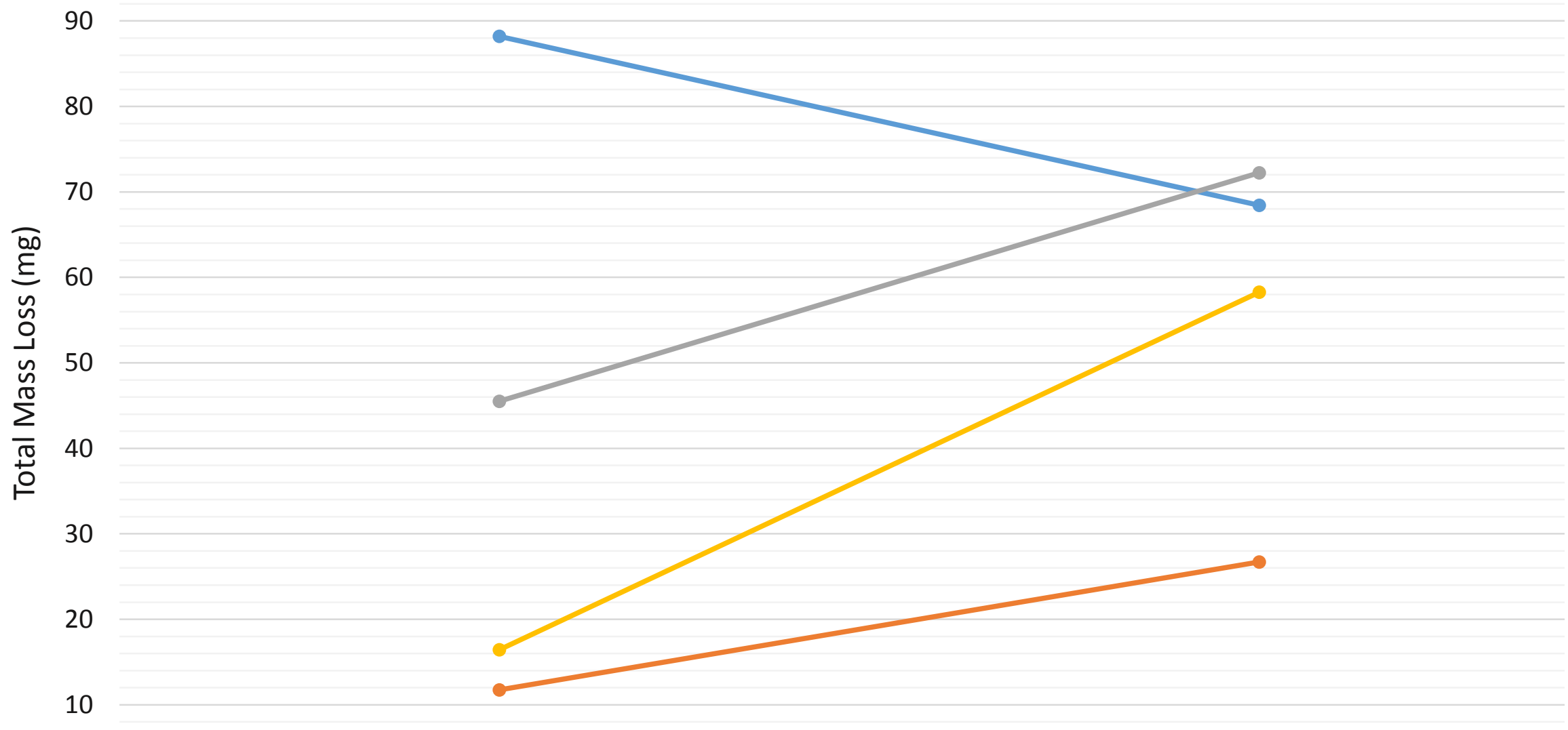

0

Angle of Attack ( $\left.{ }^{\circ}\right)$ 
Click here to download Figure: FIG8.xIsx

9.0

8.0

7.0

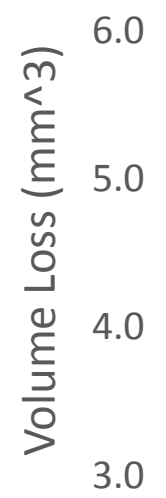

2.0

1.0

0.0
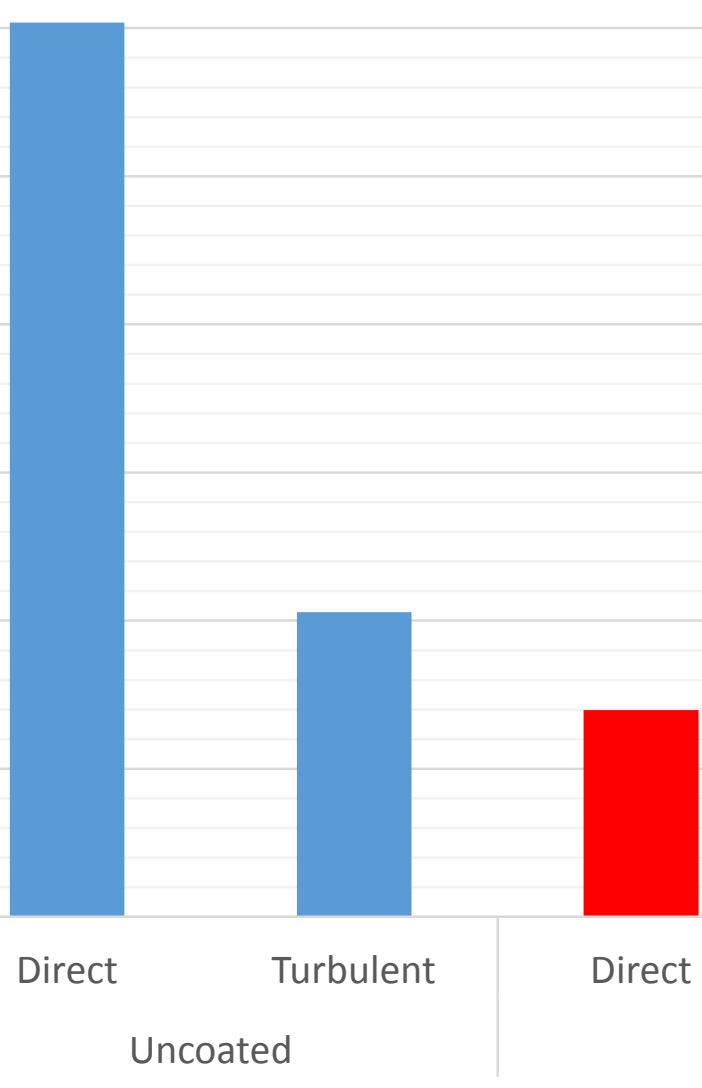

Direct

WC-CoCr

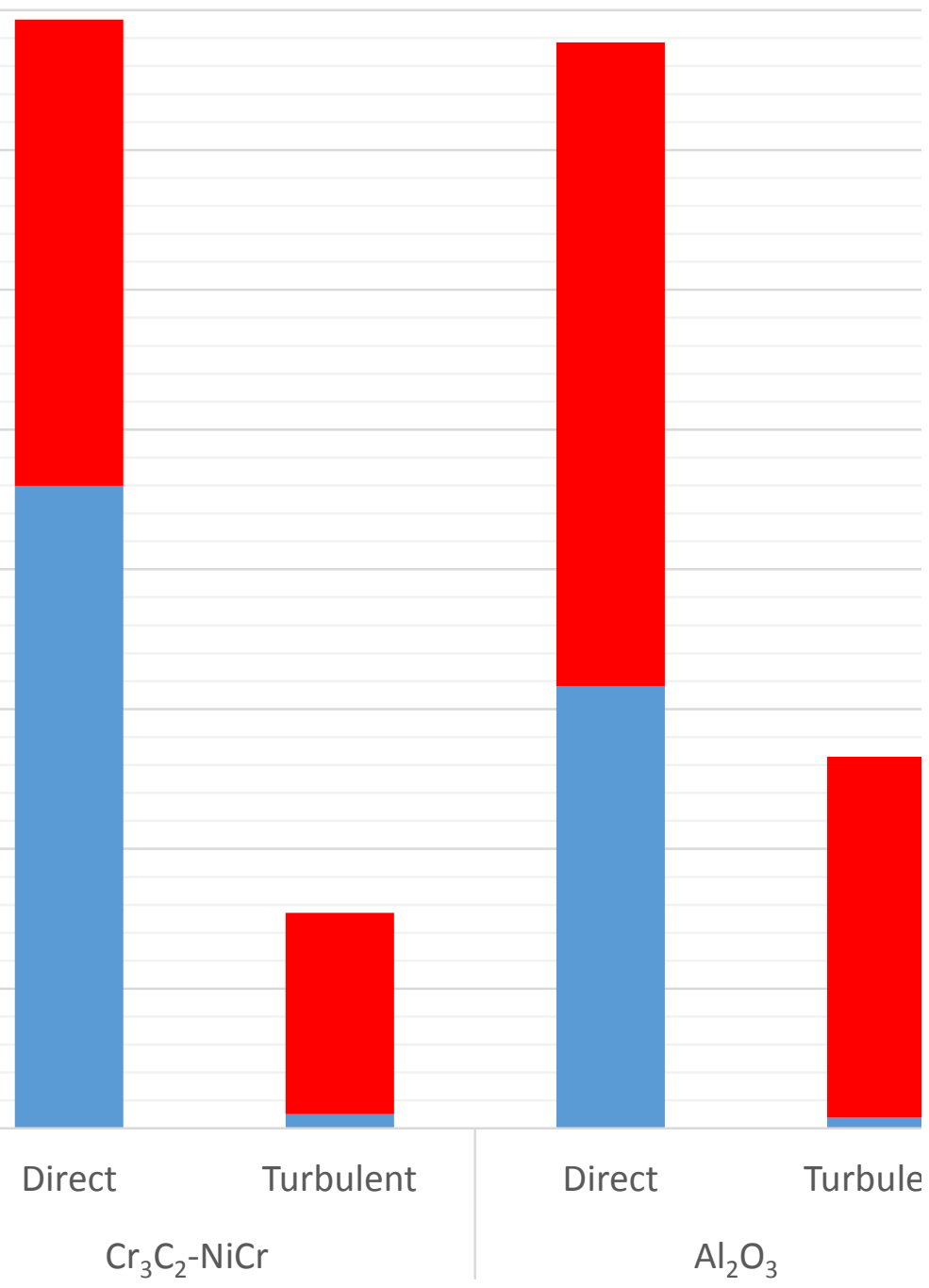

$\mathrm{Al}_{2} \mathrm{O}_{3}$ 


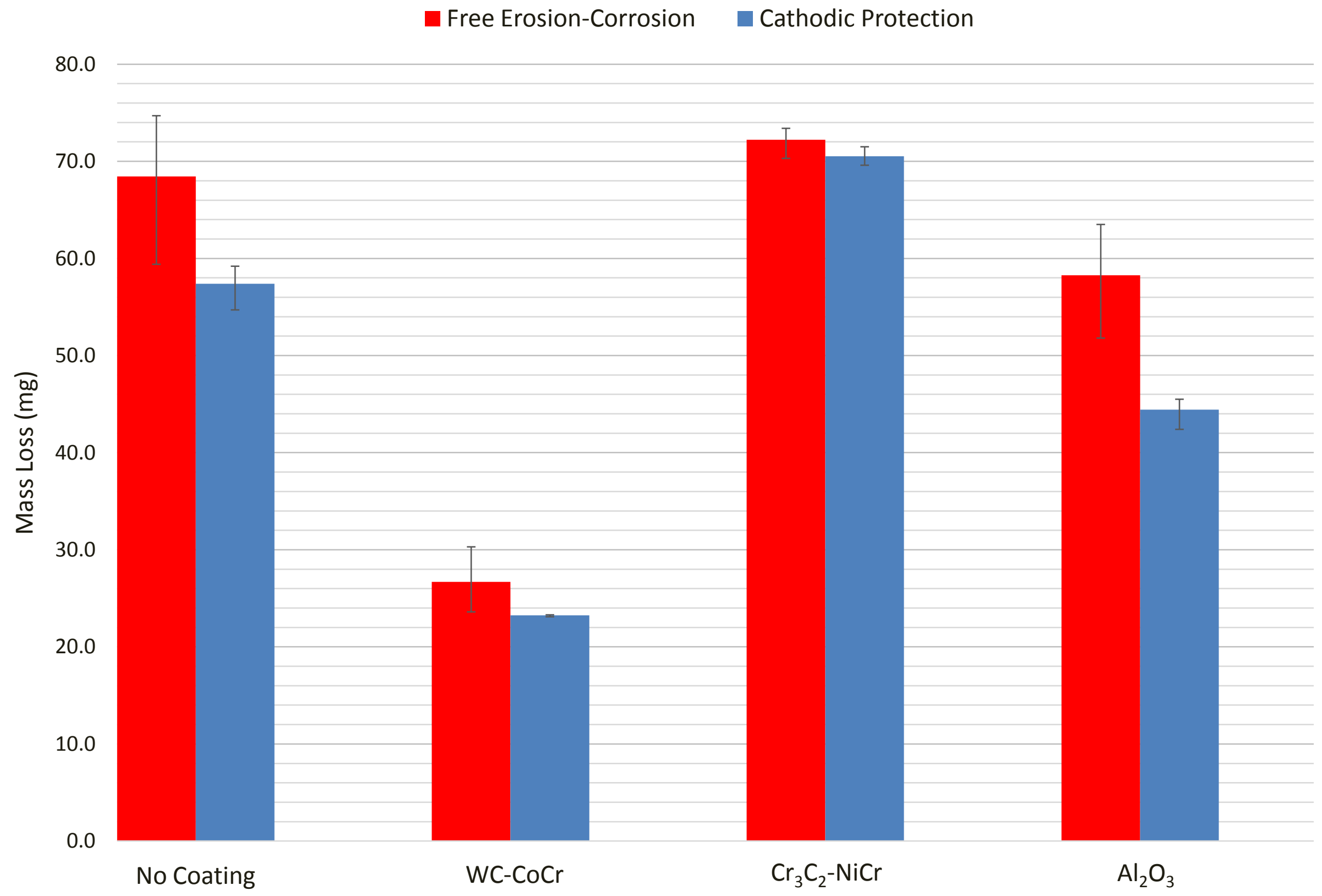




\section{Figure 10a}

Click here to download Figure: FIG10a.xIsx

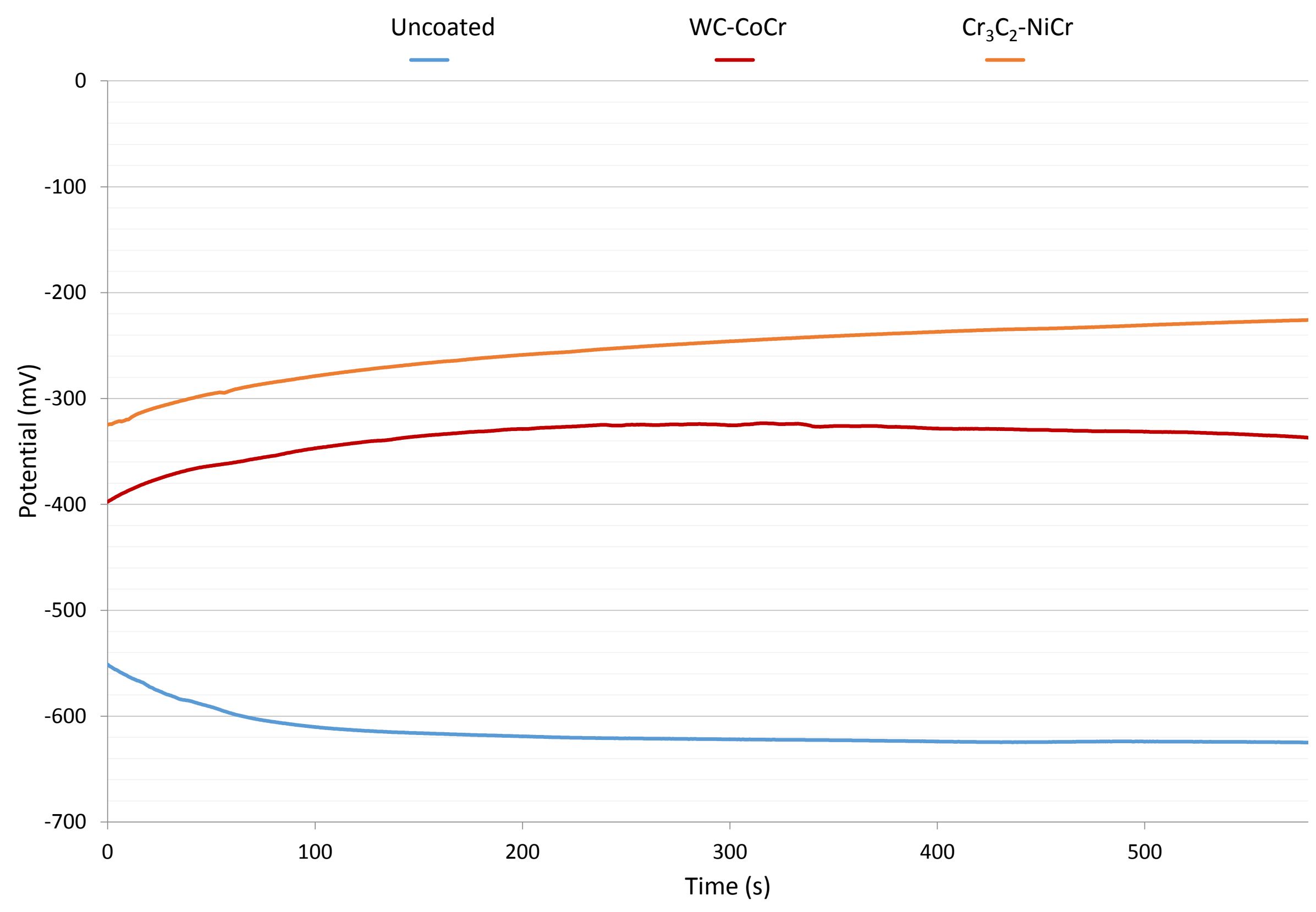




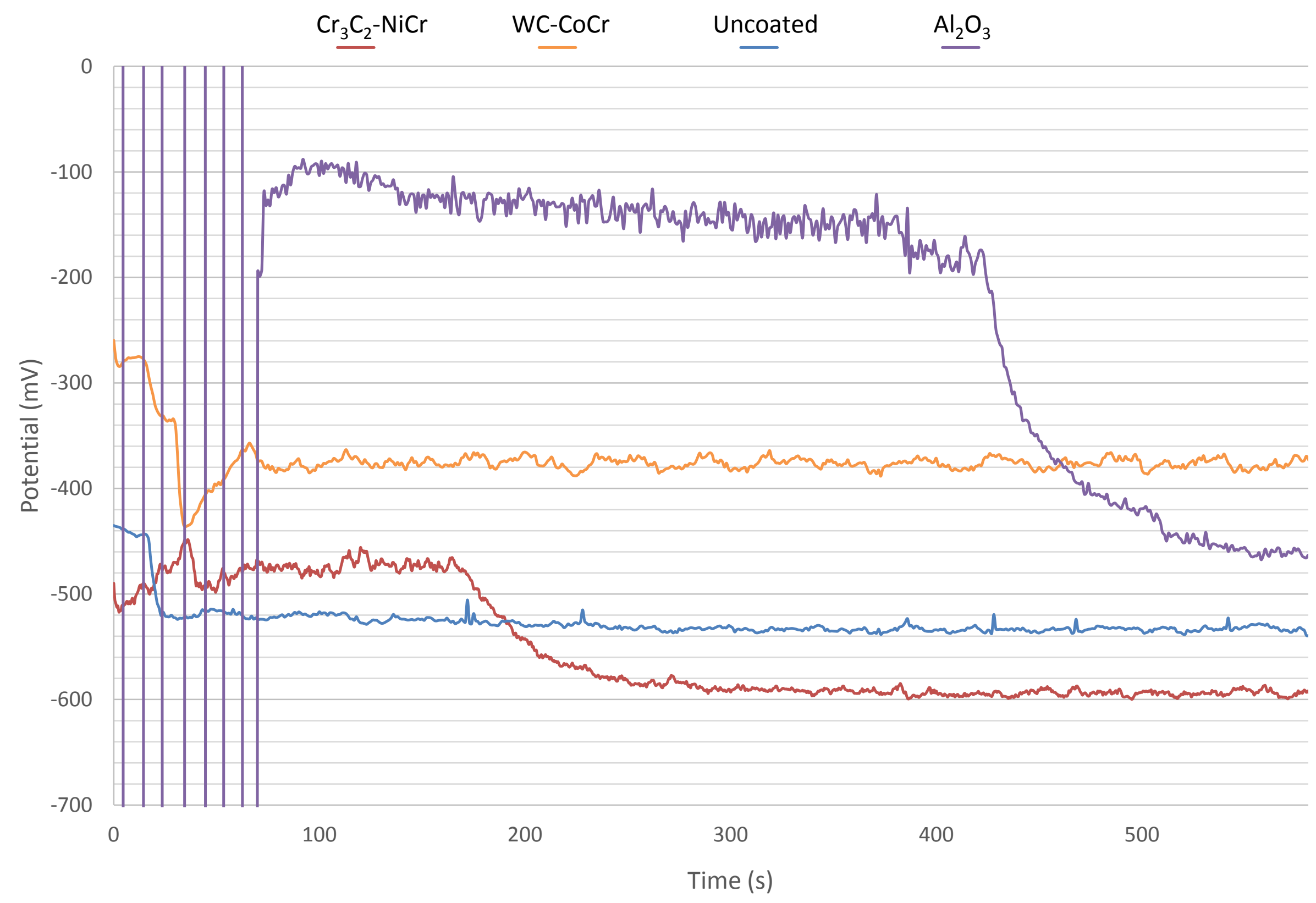


Figure 11a

Click here to download Figure: FIG11a.xIsx

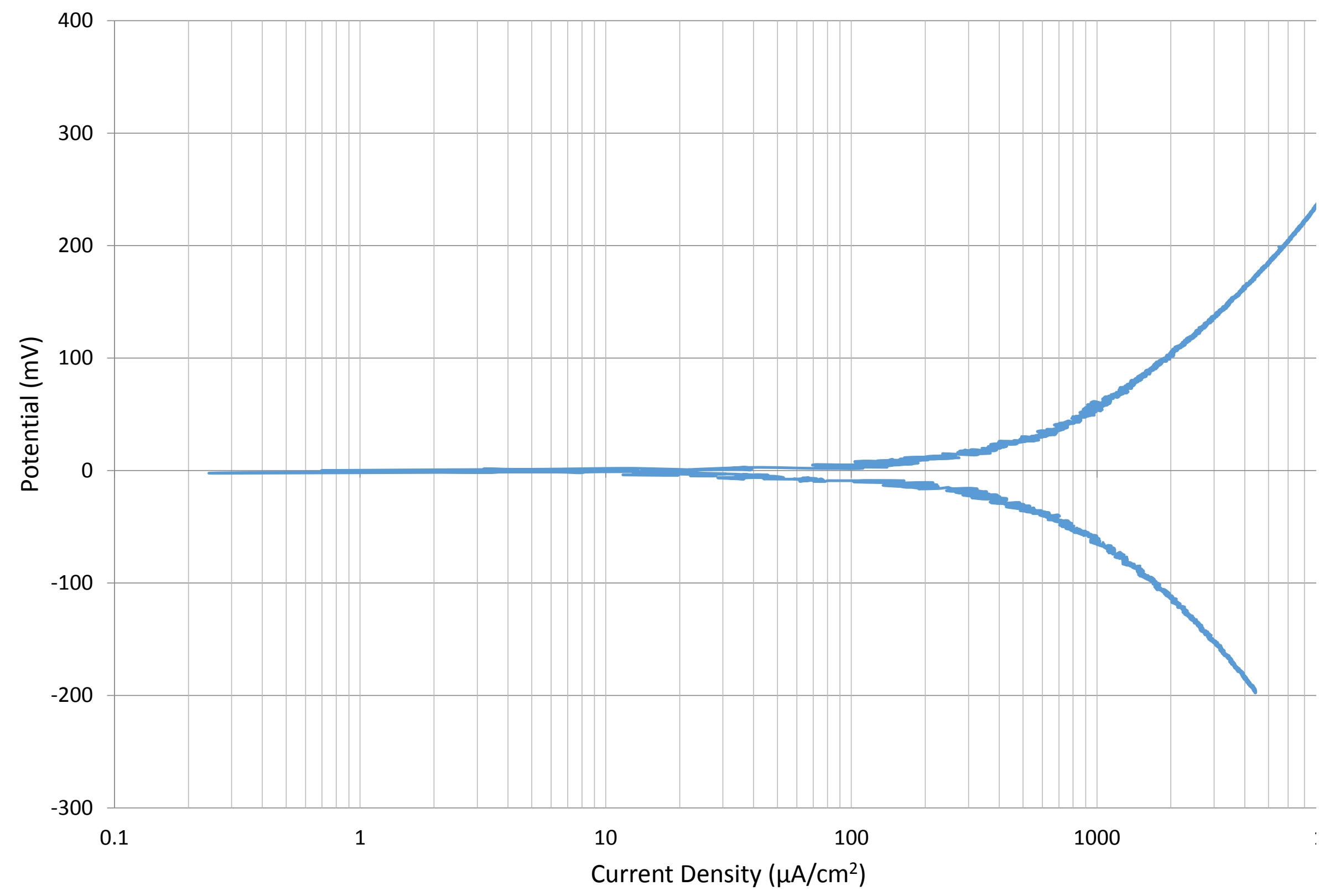




\section{Figure 116}

Click here to download Figure: FIG11b.xIsx

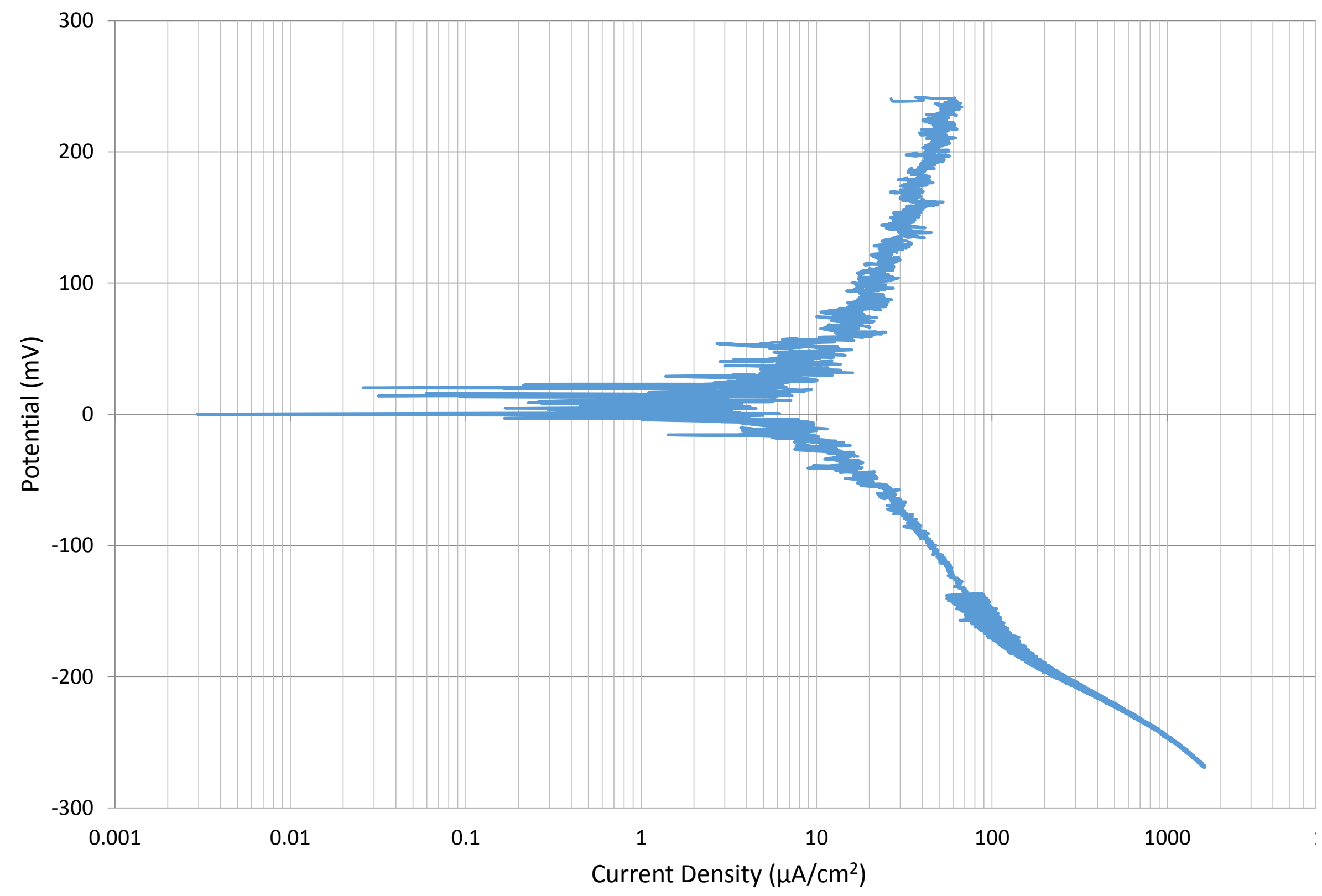




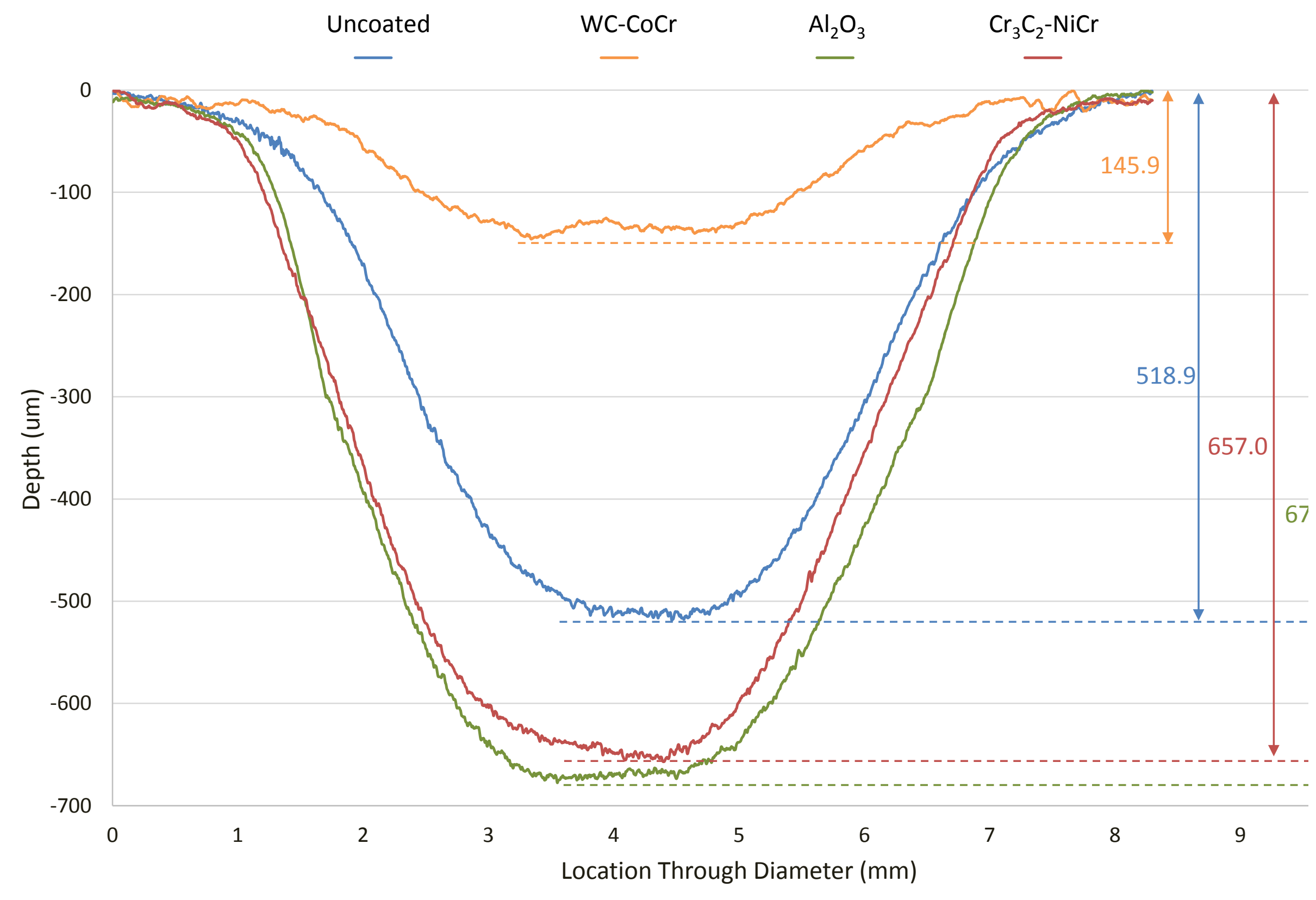


Click here to download high resolution image

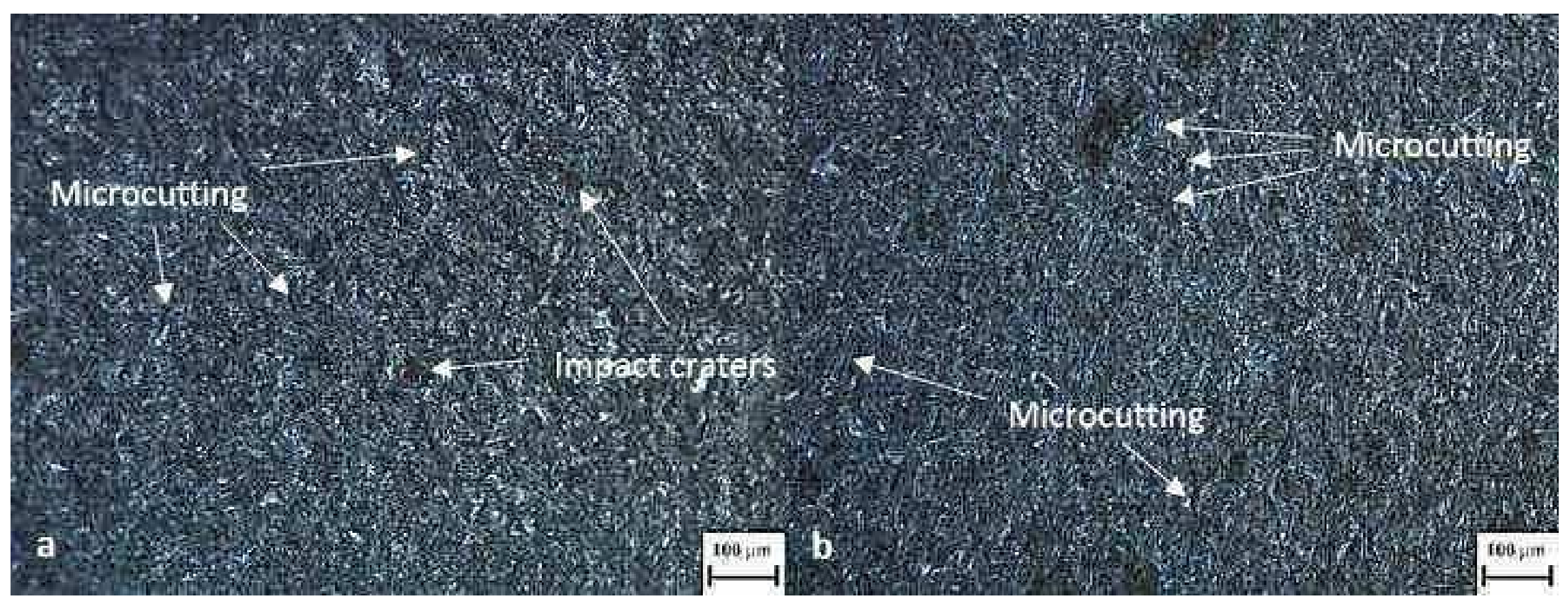

Micrecutting

b

Microcuting

$\stackrel{100}{\longrightarrow}$ 
Click here to download high resolution image

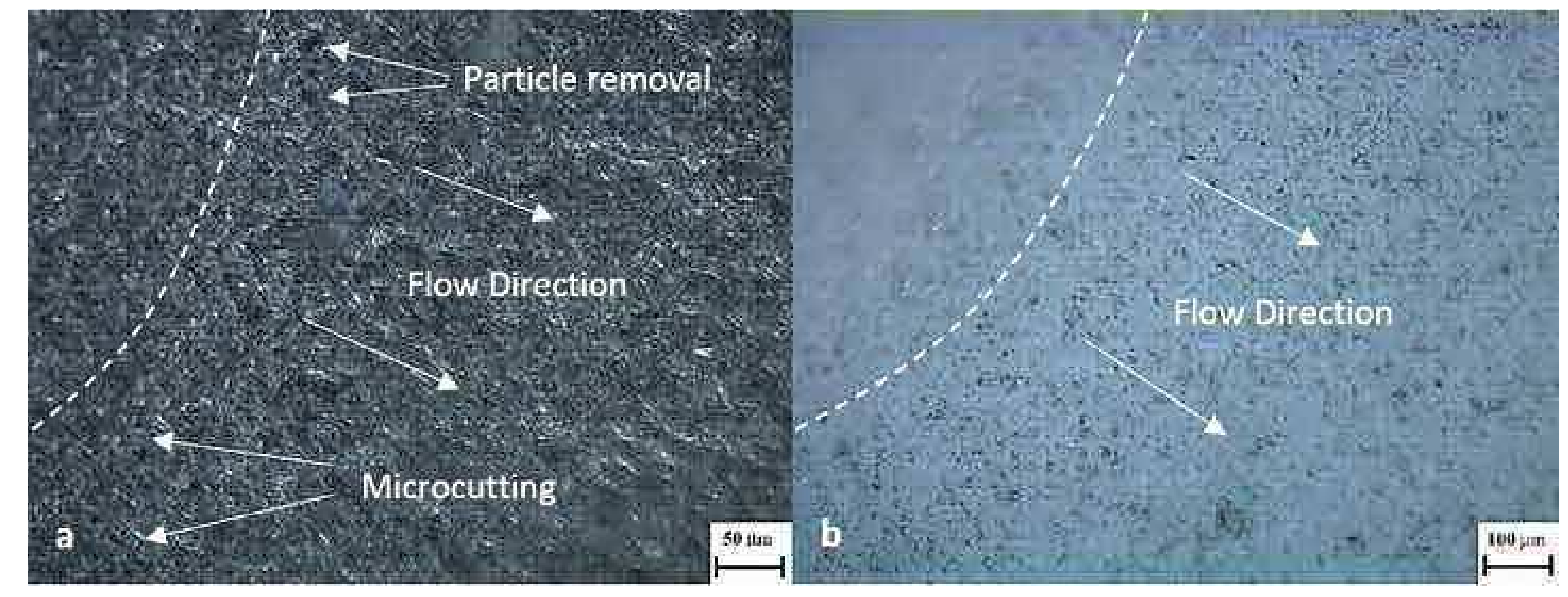


Click here to download high resolution image

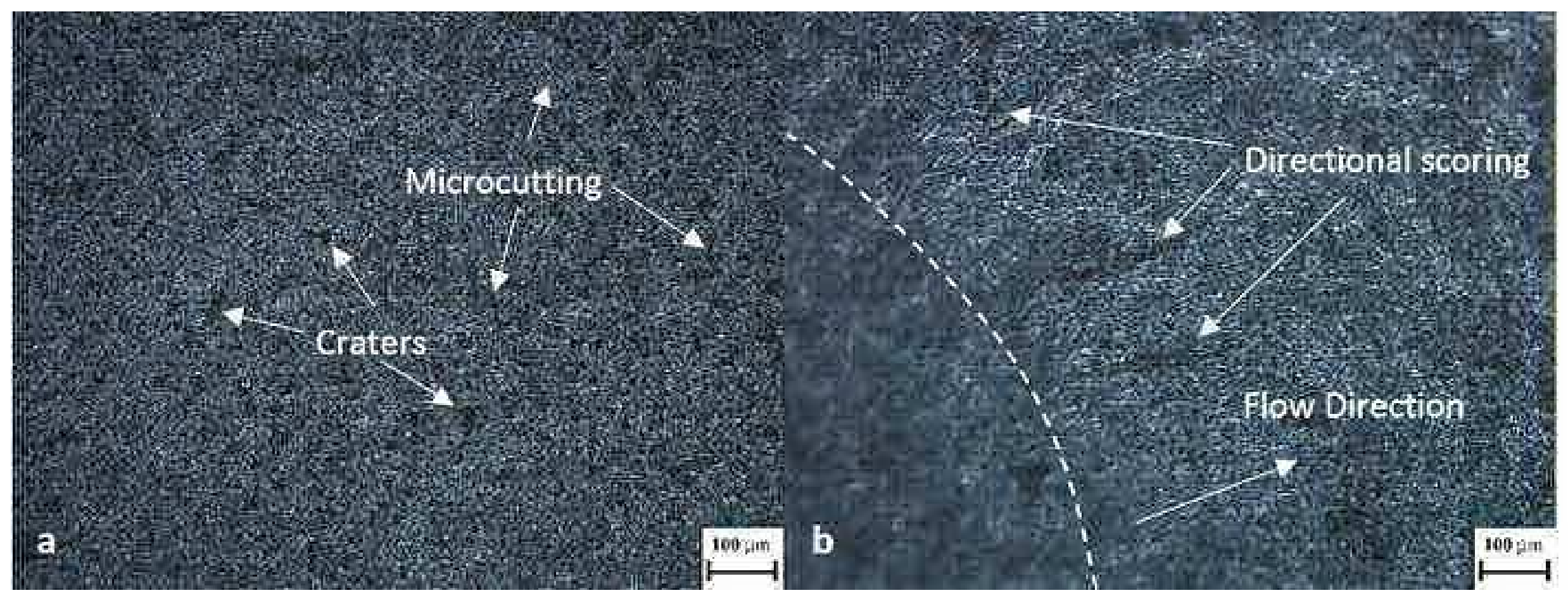

